\title{
Analytical description of power losses in a transformer operating in the dual active bridge converter
}

\author{
R. BARLIK, M. NOWAK, P. GRZEJSZCZAK*, and M. ZDANOWSKI \\ Institute of Control and Industrial Electronics, Warsaw University of Technology, Warszawa, 75 Koszykowa St., 00-662 Warsaw, Poland
}

\begin{abstract}
The paper presents an analytical approach to the determination of power losses in a high-frequency transformer operating in the dual active bridge (DAB). This transformer, having two single-phase transistor bridge inverters, couples two DC circuits that significantly differ in voltages $(280 \mathrm{~V}$ and $51 \mathrm{~V} \pm 20 \%)$. Power losses in the core and windings of the planar transformer $5600 \mathrm{VA} / 100 \mathrm{kHz}$ were calculated taking into account changes in the value and direction of the energy flow between the coupled DC circuits. These circuits represent storage or renewable energy sources and intermediate circuits of the converters used in distributed generation systems. Calculations were performed using the Steinmetz's and Dowell's equations. The analytical results have been verified experimentally.
\end{abstract}

Key words: core and windings losses, ferrite, planar transformer, Steinmetz's equation, Dowell's model, dual active bridge.

\section{Introduction}

Transformers operating at pulse voltages with higher frequencies represent major components of various types of power electronic devices, such as switch mode power supplies or isolated DC/DC converters (e.g. dual active bridge - DAB) allowing bidirectional energy flow between DC circuits (e.g. [1-3]). In the $\mathrm{DAB}$ converter the transformer provides the galvanic isolation of both coupled DC circuits, but also the possibility of energy exchange in the case of large differences between the DC voltages. In addition, these voltages may fluctuate, which is characteristic of storage and renewable energy sources [4, 5]. An important application field of these converters is also automotive and aeronautical engineering, where there are multi-voltage DC systems [6, 7].

$\mathrm{DAB}$ converters in which the hard switching technique is applied are the subject of research in many research centers reporting their investigation results in numerous publications. Those publications mainly concern converters operating at a relatively low frequency, not exceeding $20 \mathrm{kHz}$ (e.g. [2-4, 7, 8]).

In many cases, high power density and miniaturization of the electronics devices is necessary, which is also associated with material savings. This is achieved by increasing the frequency of voltage and current so as to enable the reduction of the values of the electrical parameters and geometrical dimensions of the inductors, capacitors and transformers, also in relation to DAB systems.

In the case of power electronic devices with high power densities (approx. $10 \mathrm{~kW} / \mathrm{dm}^{3}$ ), power losses generated in the individual elements must be determined, so as to be able to provide adequate cooling conditions for the inverter. These problems are the subject of many publications (e.g. [6, 9-16]). Particularly noteworthy are works $[6,10,11]$ showing the method of

\footnotetext{
*e-mail: piotr.grzejszczak@ee.pw.edu.pl
}

determining the power losses in the core and windings of high frequency transformers. However, the results reported in these publications are obtained in an experimental way and confirmed using a complex analytical description, which is difficult to use in practice. In a number of publications (e.g. [11, 13-15, 17]), attention is paid to the impact of the growth of the winding resistance for the harmonic current of the transformer, but with no reference to the operation in the DAB system.

This paper presents the analytical determination of the power losses in the core and windings of the high-frequency transformer which operates in a dual active bridge. For the determination of these losses, the Steinmetz and Dowell models were used $[18,19]$. The results of the power losses calculations include the influence of the transformer temperature different relationships between the DC voltages and varying shift modulation ratios of the DAB converter.

Section 2 presents an overview of a DAB system that includes the transformer being the main subject of this study. Section 3 provides a description of the construction of the transformer and its basic parameters. Sections 4 and 5 are devoted to the discussion of the analytical models used to determine the power loss, as well as the presentation of the results of calculations of the losses in the core and windings of the transformer under consideration. Section 6 provides the results of calculations of the total power loss and transformer energy efficiency with respect to the DAB system. In Section 7, the results obtained analytically and the results of experimental measurements are compared. Section 8 is a summary of the study, containing a brief assessment of the results and conclusions regarding the suitability of the proposed analytical description.

\section{The dual active bridge (DAB)}

Among different versions of dual active bridges, the most commonly presented in the literature are single-phase systems. They 


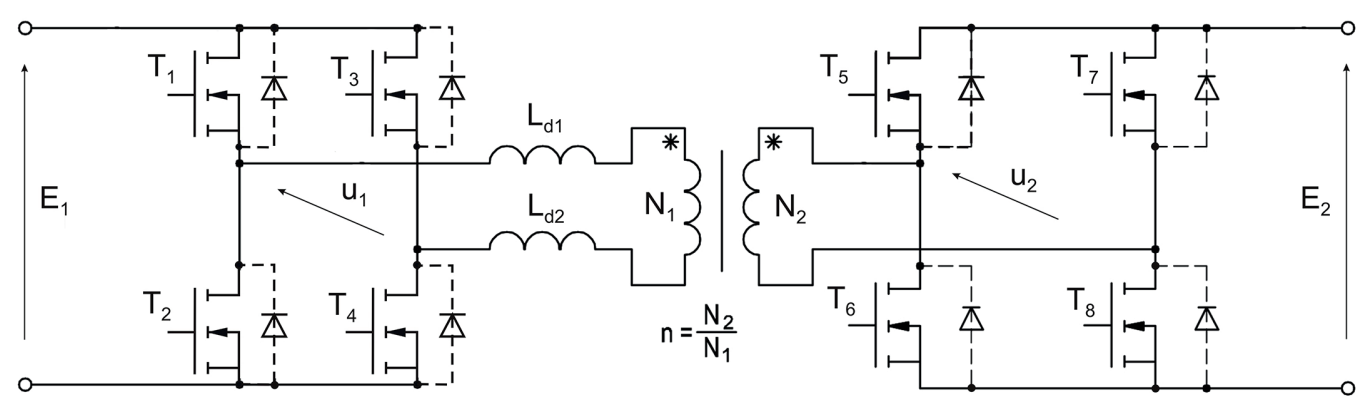

Fig. 1. Schematic diagram of the DAB system with a high-frequency transformer: $\mathrm{T} 1 \div \mathrm{T} 4-$ CoolMOS-type transistors; $\mathrm{T} 5 \div \mathrm{T} 8-\mathrm{MOS}-$ FET-type transistors

contain two H-bridges, whose AC circuits are connected, either directly or through additional inductors, to the windings of the high-frequency transformer (Fig. 1).

In the case considered in this paper the voltage $E_{l}$ is fixed at $280 \mathrm{~V}$, while the voltage $E_{2}$ may vary in the range of $51 \mathrm{~V} \pm 20 \%$, i.e. from $40.8 \mathrm{~V}$ to $61.2 \mathrm{~V}$. This means that the voltage conversion ratio, as defined by the formula

$$
k_{u}=\frac{E_{2}}{n E_{1}}
$$

may vary in the range from 0.8 to 1.2 , where $n=N_{2} / N_{1}=2 / 11$ - turns ratio of the transformer; $N_{l}, N_{2}$ - the number of turns of the high-voltage (primary) and low-voltage (secondary) winding, respectively.

Assuming that the transformer magnetizing current is negligibly small, the currents $i_{1}$ and $i_{2}$ in the two windings are dependent on the voltage difference $u_{1}$ and $u_{2} / n$ and the resultant inductance $L$ of the AC circuit. This inductance is the sum of the leakage inductance of the two transformer windings $\left(2 L_{\sigma}=0.9 \mu \mathrm{H}\right)$ and two additional inductances $\left(L_{d}=L_{d 1}+L_{d 2}=20.1 \mu \mathrm{H}\right)$, arranged on the high-voltage side. The main task of the chokes is to limit the range of the transmitted power and to reduce the sensitivity of the inverter to change in the control signal [9]. Due to the high switching frequency, $f=100 \mathrm{kHz}$, phase shift modulation is used for the control of the DAB. With this control method, each of the bridges generates a rectangular voltage of approx. $\pm 280 \mathrm{~V}$ and $\pm(40.8 \div 61.2) \mathrm{V}$ at its AC terminals (with the duty cycle being equal to $50 \%$ ). The DAB converter allows the bi-directional flow of energy between the coupled circuits $E_{1}$ and $E_{2}$ by adjusting the time shift between the rectangular voltages $u_{l}$ and $u_{2}$ of the both bridges [20].

The value of the power transferred between the circuits is given by [9]

$$
P_{E}=\frac{T}{2 L n} E_{1} E_{2} D(1-D)
$$

where $T=1 / f$ - the period of voltages $u_{1}$ and $u_{2}$ (the switching period of the transistors); $D$ - the shift ratio, defined as $D T / 2$, is a time shift between the voltages $u_{1}$ and $u_{2}$.

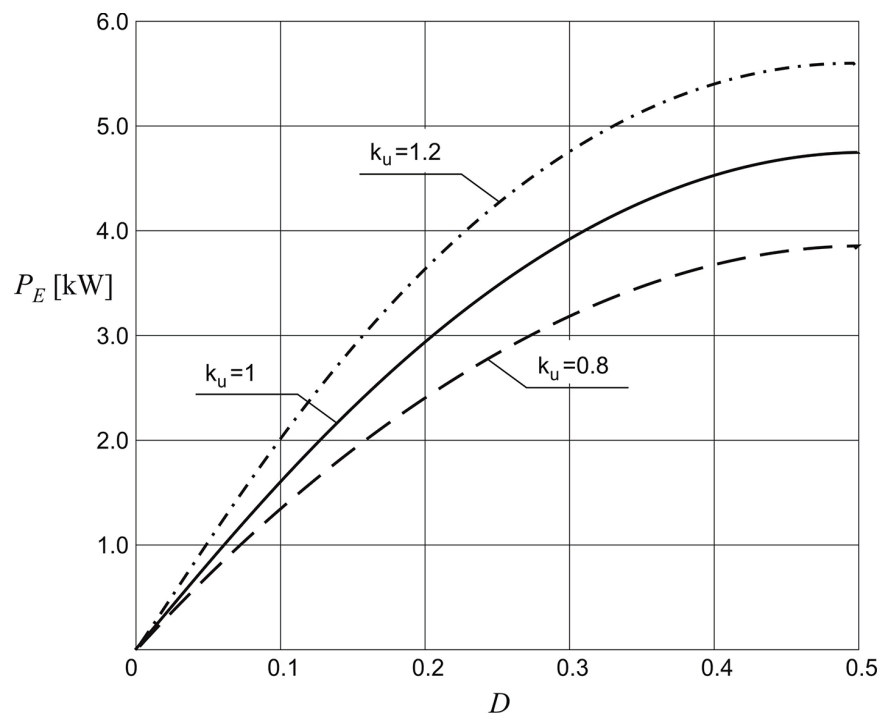

Fig. 2. Power transmitted by the DAB between the DC circuits $E_{1}$ and $E_{2}$ depending on the shift ratio $D$ at different voltage conversion ratios $k_{u}$

The power $P_{E}$ transmitted by the DAB as a function of the shift ratio $D$ for different values of the voltage conversion ratio $k_{u}$ is shown in Fig. 2.

The energy flows always from the bridge generating the leading voltage. The shift ratio $D$ is defined as positive if the energy flows from the circuit $E_{1}$ to the circuit $E_{2}$. The opposite direction of energy flow occurs at a negative time delay, i.e. if the voltage $u_{2}$ is in advance of the voltage $u_{1}$ by the time equal to $D T / 2$. In practice, the change in the duty ratio $D$ is limited to \pm 0.5 [9] due to the reduced power loss in the DAB system.

The analytical description of the power losses, proposed in this paper, is performed on the assumption that the DAB converter is fully symmetric. Therefore, only the positive shift ratio $D$ was examined.

\section{The transformer}

The subject of the study is a commercially available planar transformer with a rated power of $5600 \mathrm{VA}$ at the primary rect- 
angular voltage $\pm 360 \mathrm{~V}, 100 \mathrm{kHz}$ (Table 1). The transformer core is composed of two ferrite parts with the symbol ER 64/13/51, characterized by a circular central column (Fig. 3).

Table 1

Parameters and characteristic values of the transformer under consideration

\begin{tabular}{l|c}
\hline \multicolumn{1}{c|}{ Parameter } & Value \\
\hline rated power & $S_{T}=5600 \mathrm{VA}$ \\
\hline $\begin{array}{l}\text { rectangular primary voltage with a frequency } \\
\text { of } 100 \mathrm{kHz}\end{array}$ & $U_{l}= \pm 360 \mathrm{~V}$ \\
\hline $\begin{array}{l}\text { number of primary winding turns } \\
\text { number of secondary winding turns }\end{array}$ & $N_{1}=11$ \\
\hline $\begin{array}{l}\text { DC resistance of the primary winding at } \\
T_{T}=20^{\circ} \mathrm{C}\end{array}$ & $R_{d l}=15 \mathrm{~m} \Omega$ \\
\hline $\begin{array}{l}\text { DC resistance of the secondary winding at } \\
T_{T}=20^{\circ} \mathrm{C}\end{array}$ & $R_{d l}=0.20 \mathrm{~m} \Omega$ \\
\hline $\begin{array}{l}\text { resultant leakage inductance of the transformer } \\
\text { windings (referred to the primary side) }\end{array}$ & $2 L_{\sigma}=0.9 \mu \mathrm{H}$ \\
\hline $\begin{array}{l}\text { magnetizing inductance of the transformer } \\
\text { core material }\end{array}$ & $L_{m}=770 \mu \mathrm{H}$ \\
\hline $\begin{array}{l}\text { central core column surface area } \\
\text { component at } f=100 \mathrm{kHz} ; U_{l}=360 \mathrm{~V} ; N_{l}=11\end{array}$ & $B_{n}=0.15 \mathrm{~T}$ \\
\hline $\begin{array}{l}\text { volume of the complete core } \\
\text { two ER/64/13/51 parts) } 3 \mathrm{~F} 3\end{array}$ \\
\hline
\end{tabular}

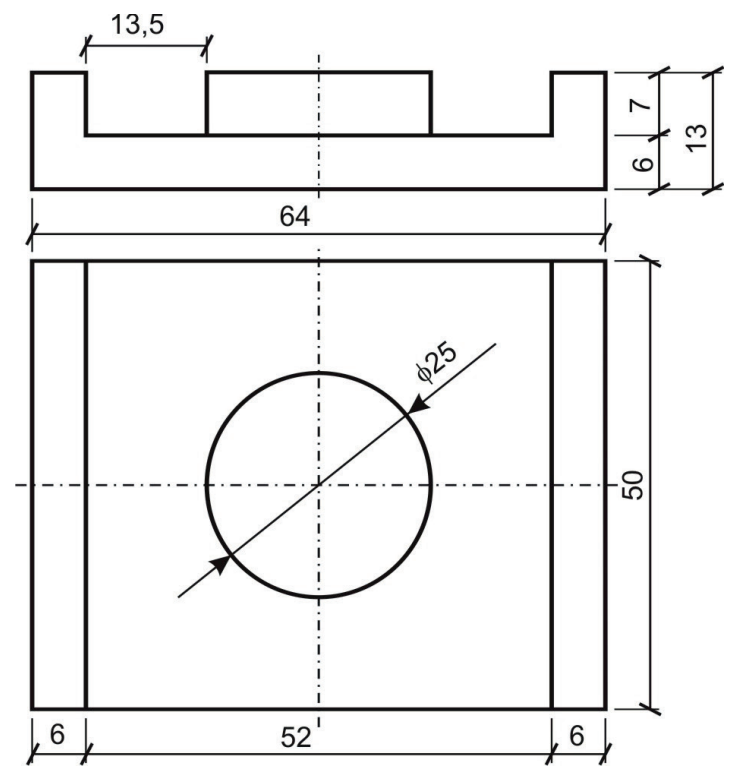

Fig. 3. A 3F3 ferrite part constituting half of the core of the SX Standex 64-56-360-28-R / RS type planar transformer [27]
In the case of a high-frequency transformer, the windings must be designed so that the magnetomotive force is minimized. Thanks to this, a limitation of the proximity effect and, as a consequence, a reduction of the eddy currents and the power losses in the windings is achieved.

In the transformer under discussion, the proximity effect has been reduced by dividing the windings into sections and placing the primary (high-voltage) and secondary (low-voltage) winding sections alternately. In addition, in order to reduce the skin effect, the primary winding is made from multilayer printed circuit boards, while the secondary winding is made from thin copper sheets. Winding technique of the high-voltage and low-voltage windings is shown in Figs. 4, 5 and 6.

The winding resistance values for DC current given in Table 1 have been calculated based on the dimensions of the printed circuit board (PCB) and the copper plates making up the winding, assuming that the resistivity of copper at a temperature of $20^{\circ} \mathrm{C}$ is $\rho=1.7 \times 10^{-8} \Omega \mathrm{m}$. The leakage and magnetizing inductances of the transformer were determined based on the analysis of the current waveform in the primary winding of the transformer for rectangular voltage $(100 \mathrm{kHz})$.

a)

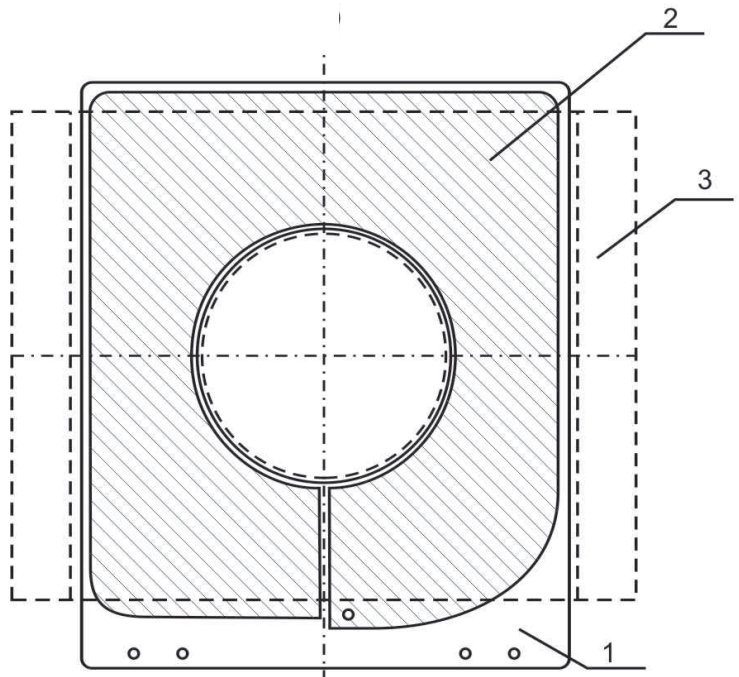

b)

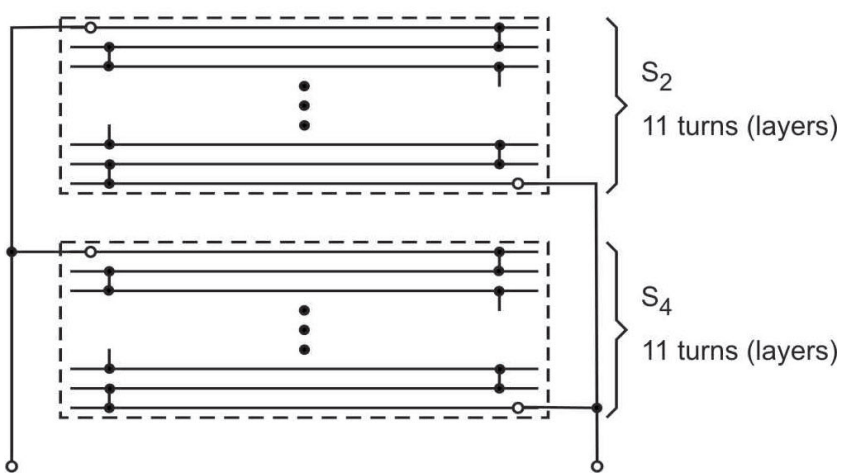

Fig. 4. The primary (high-voltage) winding: a) a multi-layer printed circuit board (11 layers, each having a copper layer thickness of $g_{1}=0.05 \mathrm{~mm}$; b) a parallel connection of two sections $\mathrm{s}_{2}$ and $\mathrm{s}_{4}$, each of which has eleven turns; 1 - laminate (PCB); 2 - copper layer; 3 - outline of the core 


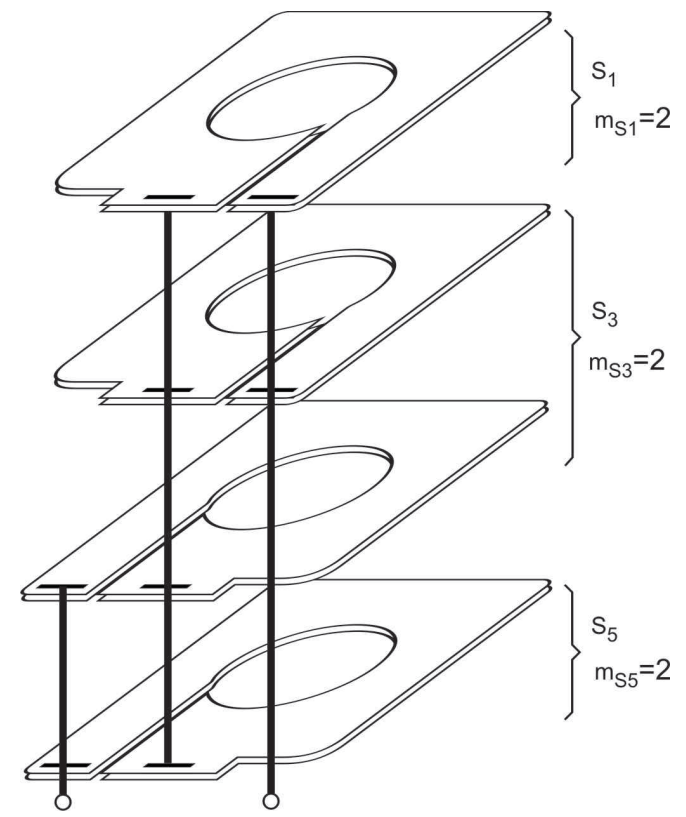

Fig. 5. The construction of the secondary (low-voltage) winding, made up of plates of copper sheets with a thickness $g_{2}=0.5 \mathrm{~mm}$ (each of the sections $\mathrm{s}_{1}$ and $\mathrm{s}_{5}$ has two layers; section $\mathrm{s}_{3}$ has four layers, whereas only two of them were considered in the calculation)

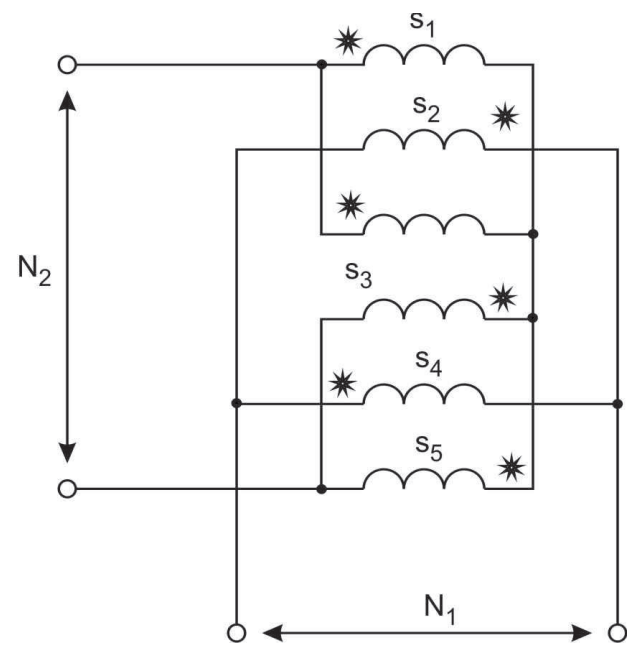

Fig. 6. The connection diagram of the primary $\left(\mathrm{s}_{2}, \mathrm{~s}_{4}\right)$ and secondary $\left(\mathrm{s}_{1}, \mathrm{~s}_{3}, \mathrm{~s}_{5}\right)$ windings

Appropriate tests were performed for the short-circuit (Fig. 7a) and the no-load (Fig. 7b) condition of the transformer, respectively. For the calculations, time intervals were chosen, in which there was an approximately constant voltage and a linear current change.

The above-mentioned parameters were used for the analysis of the power losses generated in the windings and in the core of the transformer. Due to the fact that the magnetizing inductance is much (by approx. 850 times) larger than the leakage inductance, the magnetizing current will be omitted in further discussion. a)

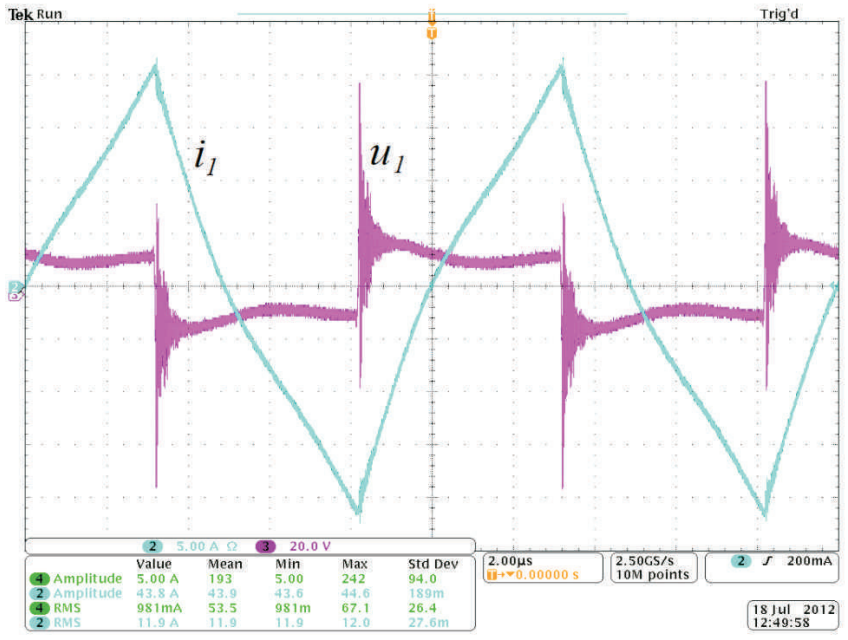

b)

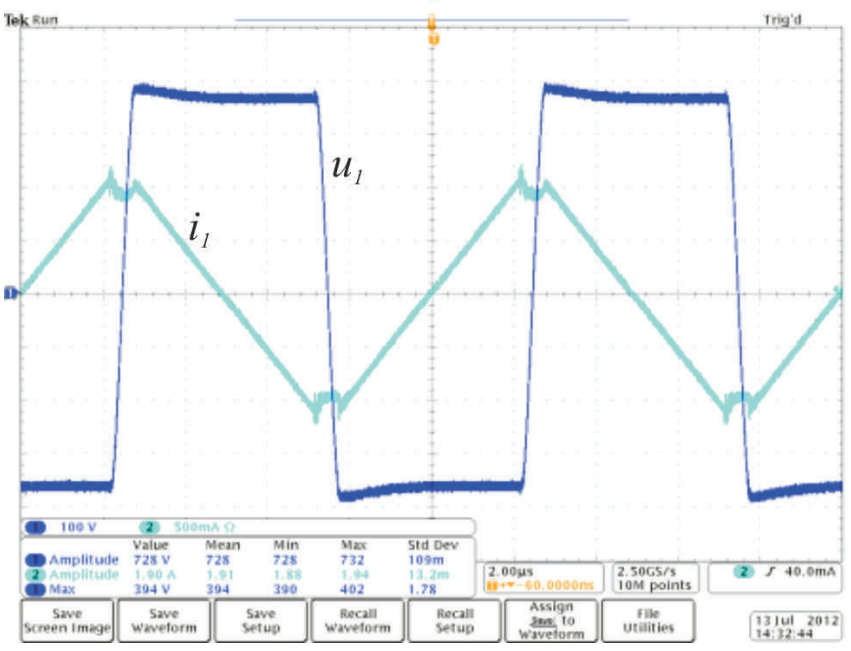

Fig. 7. The waveforms of primary winding voltage and current: a) short-circuit condition $(2 \mu \mathrm{s} / \mathrm{div} ; 20 \mathrm{~V} / \mathrm{div} ; 5 \mathrm{~A} / \mathrm{div}) ; \mathrm{b})$ no-load condition $(2 \mu \mathrm{s} / \mathrm{div} ; 100 \mathrm{~V} / \mathrm{div} ; 500 \mathrm{~mA} / \mathrm{div})$

\section{Power losses in the core}

For the analytical evaluation of the power losses generated in the ferrite core of the transformer, Steinmetz's modified equation was used, which, for rectangular voltage, takes on the following form (e.g. [11, 18])

$$
P_{F e}=\frac{8}{\pi^{2}} k f^{\alpha} B_{m}^{\beta}\left(c_{0}-c_{1} T_{T}+c_{2} T_{T}^{2}\right) V_{F e}
$$

where $P_{F e}$ - power loss in the core [W]; $f$-induction frequency $[\mathrm{Hz}] ; B_{m}$ - peak value of the induction $[\mathrm{T}] ; T_{T}$ - core temperature $\left[{ }^{\circ} \mathrm{C}\right] ; V_{\mathrm{Fe}}-$ core volume $\left[\mathrm{cm}^{3}\right]$.

The considered core is made of ferrite $3 \mathrm{~F} 3$. For this material, the Steinmetz coefficients for the frequency $f=100 \mathrm{kHz}$ and the polynomial coefficients taking into account the effects of tem- 
perature, are [11]: $k=0.25 \times 10^{-3} ; \alpha=1.60 ; \beta=2.50 ; c_{0}=1.26$; $c_{1}=1.05 \times 10^{-2}\left[{ }^{\circ} \mathrm{C}^{-1}\right] ; c_{2}=0.79 \times 10^{-4}\left[{ }^{\circ} \mathrm{C}^{-2}\right]$.

It should be noted that the polynomial taking into account the temperature influence on the core power losses is equal to 1 for the temperature $T_{T}$ being approximately equal to $30^{\circ} \mathrm{C}$ and $100^{\circ} \mathrm{C}$, respectively. The smallest value of this polynomial (approx. 0.9) occurs at a temperature of approximately $65^{\circ} \mathrm{C}$.

The maximum values of the induction $B_{m}$, which are necessary to calculate the power loss in the core, were determined based on the instantaneous values of the voltage waveforms $u_{l}$ and $u_{2}$, the induced voltage $u_{\mu}$ and the magnetic induction $B$.

According to the equivalent circuit shown in Fig. 8, the voltage $u_{\mu}$, which determines the instantaneous value of induction, is given by the formula

$$
u_{\mu}=u_{1} \frac{L_{\sigma}}{2 L_{\sigma}+L_{d}}+u_{2}^{\prime} \frac{L_{\sigma}+L_{d}}{2 L_{\sigma}+L_{d}}
$$

where $L_{\sigma}=L_{\sigma 1}=L_{\sigma 2}^{\prime}$ - leakage inductance of each winding converted to the high-voltage circuit; $L_{d}$ - total inductance of the additional chokes in the primary circuit; $u_{2}^{\prime}=u_{2} / n$ - secondary voltage converted to the primary (high-voltage) winding.

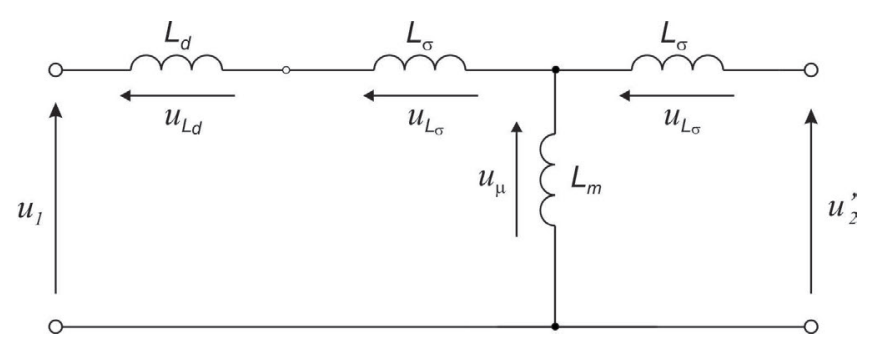

Fig. 8. Equivalent diagram with values converted to the high voltage side of the DAB system $\left(L=L_{d}+2 L_{\sigma}=21 \mu \mathrm{H}\right)$

Disregarding the voltage drops on the semiconductor devices, the voltages $u_{1}$ and $u_{2}$ have the form of alternating square waves with maximum values of, respectively, $\pm E_{1}$ and $\pm E_{2}$.

Figures $9 \div 11$ show the instantaneous values of voltage and induction at a different voltage conversion ratio and different $D T / 2$ time shifts between the voltages of the both windings. In order to simplify the waveform, it is assumed that there are no additional inductors $\left(L_{d}=0\right)$. On this assumption, there will be the least favorable working conditions of the core, in which the magnetizing voltage $u_{\mu}=\left(u_{1}+u_{2}^{\prime}\right) / 2$ and the maximum values of the induction $B_{\mathrm{m}}$ are the greatest.

In the case, where the voltage conversion ratio is $k_{u}=1$ with respect to both the positive and negative $D T / 2$ time shift (Fig. 9), it is obtained:

$$
B_{m}=\frac{T}{4} \frac{1}{N_{1} S_{F e}} E_{1}(1-D)
$$

where $S_{F e}$ is cross-sectional area of the core. a)
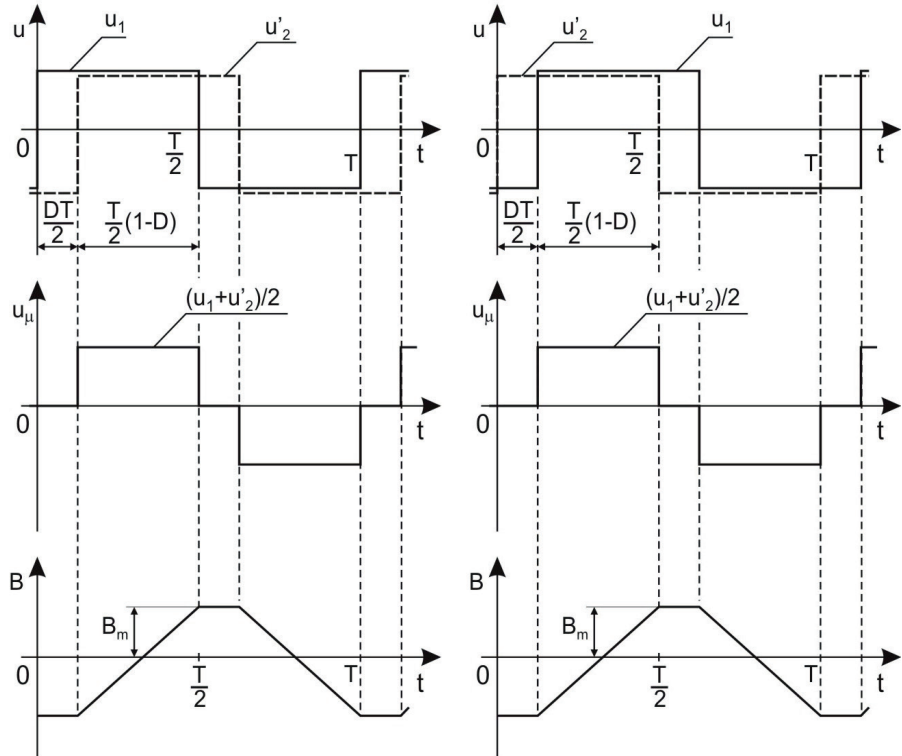

Fig. 9. Simplified waveforms of voltages on either of the transformer windings, the magnetizing voltage and the magnetic induction at $k_{u}=1:$ a) $D T / 2>0$; b) $D T / 2<0$ a)

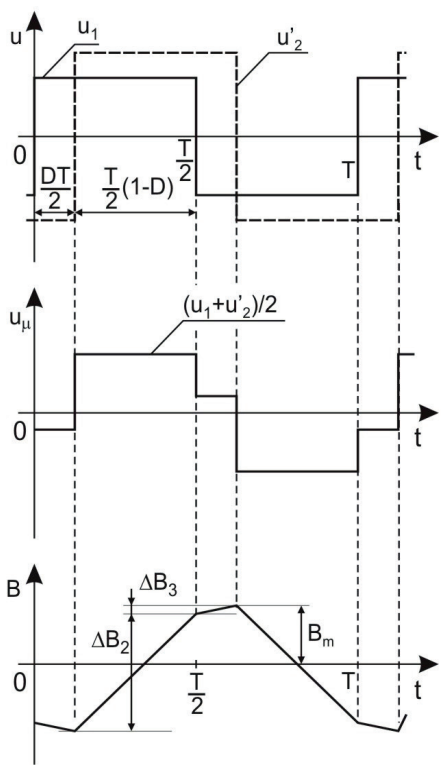

b)

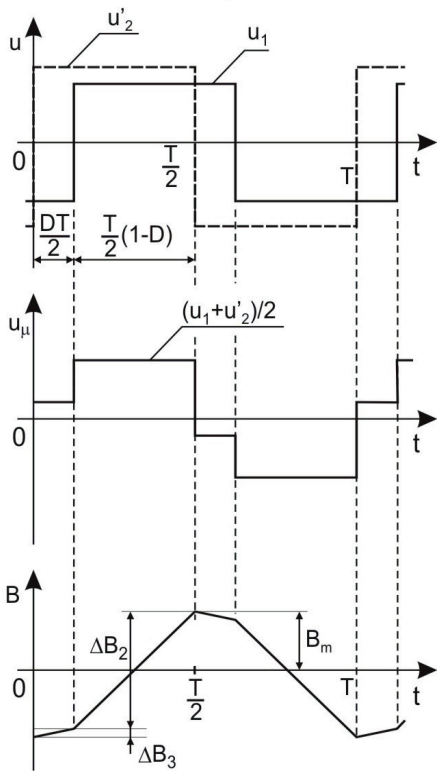

Fig. 10. Simplified waveforms of voltages on either of the transformer windings, the magnetizing voltage and the magnetic induction at $k_{u}>1:$ a) $D T / 2>0$; b) $D T / 2<0$

With a voltage conversion ratio of $k_{u}>1$, then for a time shift of either $D T / 2>0$ (Fig. 10a) or $D T / 2<0$ (Fig. 10b), it can be written:

$$
B_{m}=\frac{\Delta B_{2}+\Delta B_{3}}{2}=\frac{T}{4} \frac{1}{N_{1} S_{F e}} E_{1} \frac{1}{2}\left(1-2 D+k_{u}\right)
$$


a)

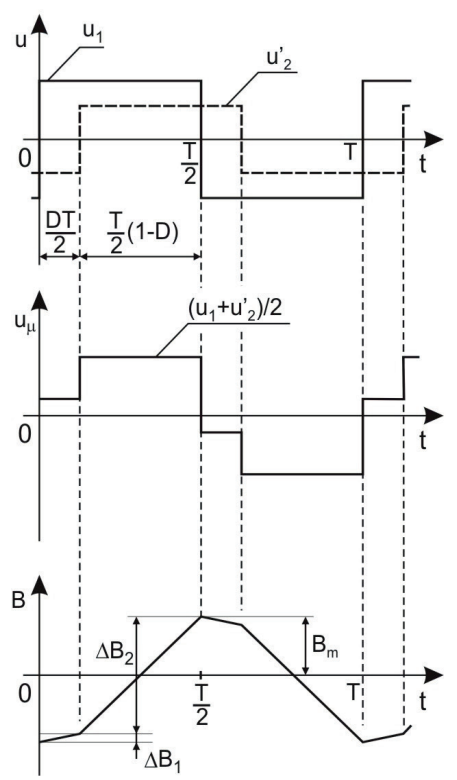

b)

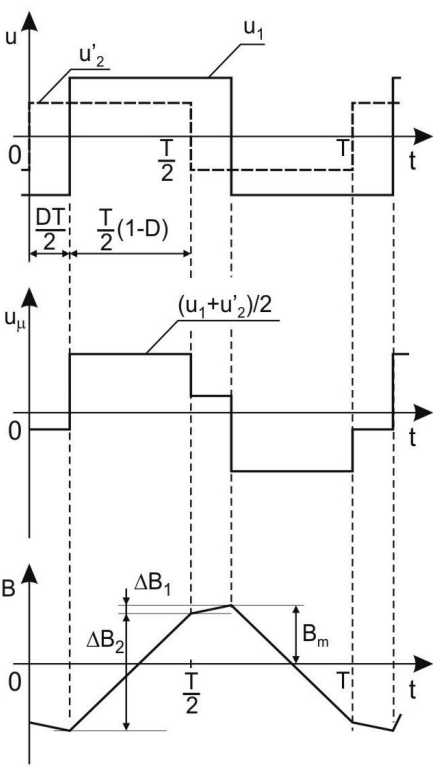

Fig. 11. Simplified waveforms of voltages on either of the transformer windings, the magnetizing voltage and the magnetic induction at $k_{u}<1$ : a) $D T / 2>0$; b) $D T / 2<0$

In case of the conversion ratio being $k_{u}<1$, then for both positive and negative $D T / 2$ time shifts (Fig. 11) we have

$$
B_{m}=\frac{\Delta B_{1}+\Delta B_{2}}{2}=\frac{T}{4} \frac{1}{N_{1} S_{F e}} E_{1} \frac{1}{2}\left[1+k_{u}(1-2 D)\right]
$$

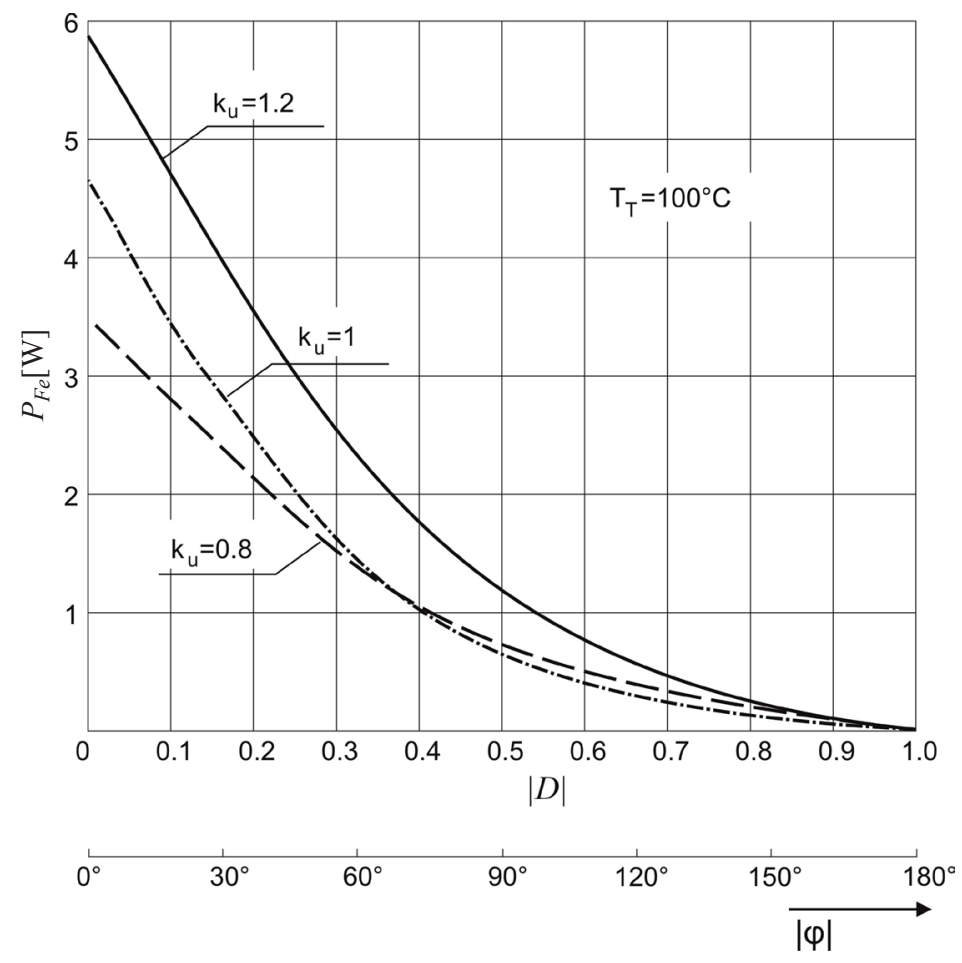

Fig. 12. Core power losses of the planar transformer versus the shift ratio $|D|$ for the voltage conversion ratio $k_{u}$ being equal to $0.8,1$ and 1.2 (the core temperature $T_{T}$ equals $30^{\circ} \mathrm{C}$ or $100^{\circ} \mathrm{C}$ )

Equations $(6 \div 8)$ were used for the calculation of the $B_{m}$ induction peak values, based on which the core power losses were determined. The values of these losses as a function of the shift ratio $D$ (absolute value) for different voltage conversion ratios $k_{u}$ are shown in Fig. 12. It is worth noting that for a core temperature of $20^{\circ} \mathrm{C}$, core power losses are larger by $8.2 \%$ compared to the losses at $30^{\circ} \mathrm{C}$ and $100^{\circ} \mathrm{C}(4)$.

\section{Power losses in the windings of the transformer}

5.1. Windings resistances. To reduce the resistance for alternating current, the primary and secondary windings are divided into sections and arranged, as shown in Fig. 13. Based on Dowell's model, the AC resistance of the $j$-th winding section $\left(R_{a c(j)}\right)$ consisting of $m_{s}$ layers can be expressed with the following relationship (e.g. [19-24]):

$$
\begin{aligned}
R_{a c(j)} & =R_{d(j)} y\left[\frac{\sinh (2 y)+\sin (2 y)}{\cosh (2 y)-\cos (2 y)}+\right. \\
& \left.+\frac{2}{3}\left(m_{s}^{2}-1\right) \frac{\sinh (y)-\sin (y)}{\cosh (y)+\cos (y)}\right]=K_{R(j)} R_{d(j)}
\end{aligned}
$$

where $R_{a c(j)}, R_{d(j)}$ - respectively, the AC and DC resistances of the $j$-th winding section; $K_{R(j)}$ - the ratio between the AC resistance and the DC resistance, which takes into account the skin and proximity effect for sinusoidal current with a frequency of $f ; m_{s}$ - the effective number of layers in the considered winding section (taken for calculation).

The term $y$ occurring in formula (9) represents the relative thickness of the layer and is expressed as follows:

$$
y=\sqrt{k_{w}} \frac{h}{\delta}
$$

where $k_{\mathrm{w}}$ - the copper fill factor (for copper sheets and PCBs, $\left.k_{w} \approx 1\right) ; h$ - the effective layer thickness which is equal to the thickness of the copper path (for PCB, $g_{1}=0.05 \mathrm{~mm}$ ) and the thickness of copper sheet $\left(g_{2}=0.5 \mathrm{~mm}\right) ; \delta$ - skin depth.

The depth of the skin effect, being characteristic of the material from which the windings are made, is given by the following relationship:

$$
\delta=\sqrt{\frac{\rho}{\pi f \mu}}
$$

where $f$-sinusoidal current frequency; $\mu, \rho$-magnetic permeability and resistivity of the winding. For copper conductors at the current frequency $f=100 \mathrm{kHz}$ and temperature $20^{\circ} \mathrm{C}$, the skin depth is $\delta \approx 0.22 \mathrm{~mm}$.

According to equations (10) and (11) the relative thickness of the layers of primary and secondary windings are respectively: $\mathrm{y}_{\text {prim }}=0.23, \mathrm{y}_{\mathrm{sec}}=2.3$.

The number of sections and layers taken for calculations may be different from the number of the actual sections and 


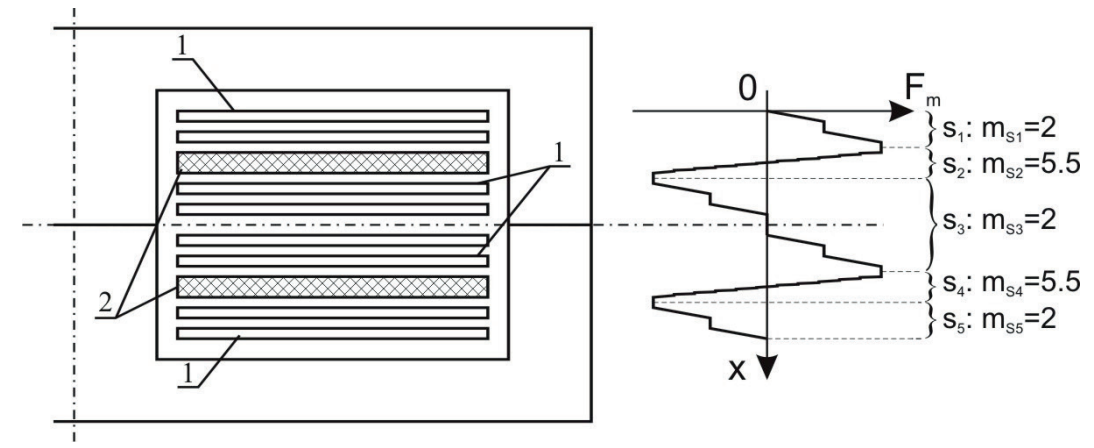

Fig. 13. Cross-sectional view of the winding configurations and the indicative distribution of the magnetomotive force according to Dowell's assumption; 1 - sections of the secondary winding made up of copper sheet; 2 - section of the primary winding made up of multilayer printed circuit boards (PCB)

layers. In order to determine the sections and layers taken into account in calculations, it is convenient to draw up an indicative sketch representing the distribution of the magnetomotive force $F_{m}(x)$ along the x-axis perpendicular to the layers and the leakage flux (Fig. 13). The number of $m_{s}$ layers include only those layers which lie between the extremes of the magnetomotive force and the $x$ axis.

The primary winding, which is made up of multilayer printed circuit board, has two sections, $\mathrm{s}_{2}$ and $\mathrm{s}_{4}$, connected in parallel, each of them having 11 turns. The number of layers in two sections is identical, being $\mathrm{m}_{\mathrm{s} 2}=\mathrm{m}_{\mathrm{s} 4}=5.5$. The secondary winding, made of copper sheet, consists of three sections. The sections $\mathrm{S} 1$ and $\mathrm{S} 5$ have two layers $\left(\mathrm{m}_{\mathrm{s} 1}=\mathrm{m}_{\mathrm{s} 5}=2\right)$, while the section S3 has four layers, but in this case, the number of layers equal to two $\left(\mathrm{m}_{\mathrm{s} 3}=2\right)$ should be taken for calculation.

The AC resistance ratio, expressed as the ratio of AC resistance to DC resistance, for a given section $\left(K_{R(j)}=R_{a c(j)} / R_{d(j)}\right)$ can be either calculated using equation (9) or red out from the graph prepared based on this relationship, which is shown in Fig. 14.

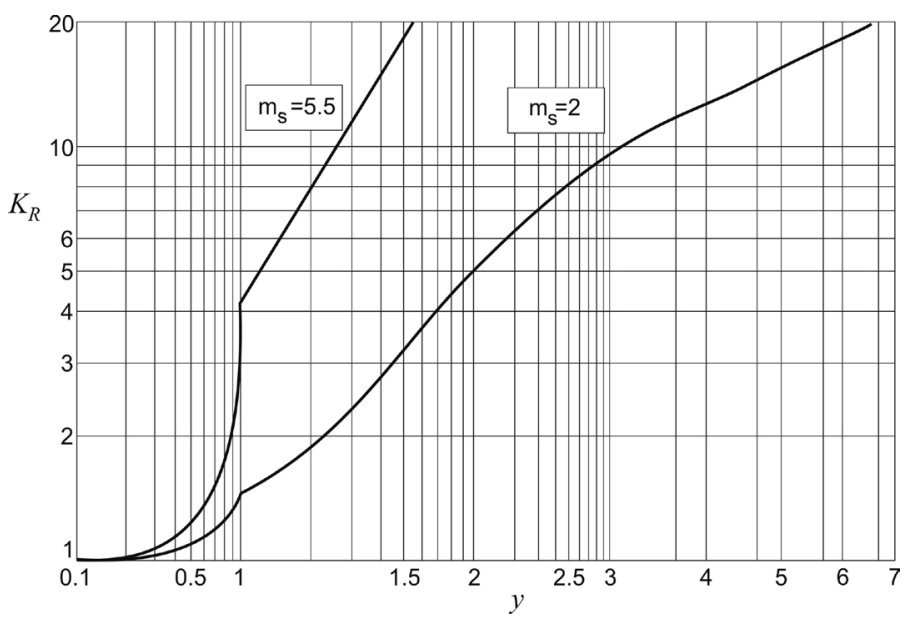

Fig. 14. The AC resistance ratio $K_{R}$ of the planar transformer windings depending on the relative thickness of the layer $y$ with the number of layers $m_{s}$ as a parameter
In the case of the primary winding, for which $y<1.5$, formula (9) can be approximated with sufficient accuracy with a simple expression in the following form [25]:

$$
K_{R}=1+\frac{5 m_{s}^{2}-1}{45} y^{4}
$$

Equations (9-12) and the graphs shown in Fig. 14 both refer to the currents of sinusoidal waveforms with a frequency $f$. However, in the windings of a transformer operating in the DAB system, distorted currents occur. The stray field, induced by higher current harmonics, induces eddy currents that cause an additional increase in the resistances of the windings.

Power losses in the copper should be calculated by summing the losses for each current harmonic according to the following formula (e.g. [15]):

$$
P_{C u}=P_{C u 1}+P_{C u 2}=\sum_{k=1}^{K} I_{1(k)}^{2} R_{a c 1(k)}+\sum_{k=1}^{K} I_{2(k)}^{2} R_{a c 2(k)}
$$

where $P_{C u 1}, P_{C u 2}, P_{C u}$, - power losses generated in the highand low-voltage windings and the total copper losses; $k$-index for current harmonics; $I_{1(k)}, I_{2(k)}-$ RMS values of the $k^{\text {th }}$ current harmonics in the high- and low-voltage windings; $R_{a c l(k)}, R_{a c 2(k)}$ - AC resistances of the windings at the $k^{\text {th }}$ harmonic; $K$ - the order of the highest harmonic considered in calculation.

To determine the $R_{a c l(k)}$ and $R_{a c 2(k)}$ it is necessary to take into account the influence of the frequency of the current harmonics at the skin depth, and therefore also the relative thickness of the windings layers, which is given by the formula below:

$$
y_{(k)}=y \sqrt{k}
$$

where $y_{k}$ - relative layer thickness for the frequency $f_{(k)}=k f$; $y$ - relative layer thickness for the base frequency $f=f_{(1)}$.

The rise in winding temperature is the cause of the increase of copper resistivity. Increasing the resistivity results in an increase in winding resistance for DC current, but also a decrease in the relative thickness of the layers $(10,11)$ and a reduction in the skin and proximity effects. As a consequence, the $\mathrm{AC}$ to $\mathrm{DC}$ resistance ratio is reduced. 
Table 2 shows the ratios $K_{R 1}=R_{a c 1} / R_{d 1}$ and $K_{R 2}=R_{a c 2} / R_{d 2}$, and the resistances of the high- and low-voltage windings for several frequencies $f_{(k)}=k f$ corresponding to the frequencies of the current harmonics, for winding temperatures of $20^{\circ} \mathrm{C}$ and $100^{\circ} \mathrm{C}$.

Table 2

$\mathrm{AC}$ resistance ratios and windings resistances for several current harmonics and the temperatures $20^{\circ} \mathrm{C}$ and $100{ }^{\circ} \mathrm{C}$

\begin{tabular}{|c|c|c|c|c|c|c|c|c|}
\hline \multirow{3}{*}{-} & \multicolumn{4}{|c|}{ High-voltage (primary) winding } & \multicolumn{4}{|c|}{$\begin{array}{c}\text { Low-voltage (secondary) } \\
\text { winding }\end{array}$} \\
\hline & \multicolumn{2}{|c|}{$T_{T}=20^{\circ} \mathrm{C}$} & \multicolumn{2}{|c|}{$T_{T}=100^{\circ} \mathrm{C}$} & \multicolumn{2}{|c|}{$T_{T}=20^{\circ} \mathrm{C}$} & \multicolumn{2}{|c|}{$T_{T}=100^{\circ} \mathrm{C}$} \\
\hline & \multicolumn{2}{|c|}{$R_{d 1}=15 \mathrm{~m} \Omega$} & \multicolumn{2}{|c|}{$\begin{aligned} R_{d 1} & =19.90 \\
& \mathrm{~m} \Omega\end{aligned}$} & \multicolumn{2}{|c|}{$\begin{array}{l}R_{d 2}=0.2 \\
\mathrm{~m} \Omega\end{array}$} & \multicolumn{2}{|c|}{$\begin{array}{c}R_{d 2}=0.264 \\
\mathrm{~m} \Omega\end{array}$} \\
\hline$k$ & $K_{R 1}$ & $\begin{array}{c}R_{a c 1} \\
{[\mathrm{~m} \Omega]}\end{array}$ & $K_{R 1}$ & $\begin{array}{c}R_{a c 1} \\
{[\mathrm{~m} \Omega]}\end{array}$ & $K_{R 2}$ & $\begin{array}{c}R_{a c 2} \\
{[\mathrm{~m} \Omega]}\end{array}$ & $K_{R 2}$ & $\begin{array}{c}R_{a c 2} \\
{[\mathrm{~m} \Omega]}\end{array}$ \\
\hline 1 & 1.008 & 15.12 & 1.0065 & 19.93 & 7.0 & 1.4 & 5.8 & 1.53 \\
\hline 3 & 1.0085 & 15.13 & 1.058 & 20.96 & 11.5 & 2.3 & 11.3 & 2.98 \\
\hline 5 & 1.21 & 18.15 & 1.16 & 23.00 & 14.0 & 2.8 & 13.0 & 3.43 \\
\hline 7 & 1.40 & 21.00 & 1.32 & 26.07 & 18.0 & 3.7 & 17.0 & 4.49 \\
\hline 9 & 1.67 & 25.05 & 1.52 & 30.15 & 19.5 & 3.9 & 18.0 & 4.75 \\
\hline 11 & 1.95 & 29.50 & 1.77 & 35.14 & 22.0 & 4.4 & 19.5 & 5.15 \\
\hline
\end{tabular}

Due to the ratios $K_{R I}$ and $K_{R 2}$ decreasing with increasing temperature, the resistance increase for $\mathrm{AC}$ current is smaller than for DC current.

5.2. Winding currents. Disregarding the magnetizing current, the currents in the windings of the transformer depend on the winding voltage differences $u_{1}$ and $u_{2}$ and the resultant inductance $L$ occurring in the AC circuit of the DAB (Fig. 1, Fig. 15).

Based on Fig. 15, the effective current $I_{l}$ in the high-voltage winding can be described with the following formulas [7], [9]: - in the case where $k_{u}<1$

$I_{1}=\sqrt{\frac{2}{T}\left[\frac{1}{3} I_{L 3}^{2} t_{A}+\frac{1}{3} I_{L 2}^{2} t_{B}+\left(I_{L 2}^{2}+\frac{1}{3} \Delta I_{L}^{2}+I_{L 2} \Delta I_{L}\right) t_{C}\right]}$

- in the case where $k_{u}=1$

$$
I_{1}=I_{L 3} \sqrt{\frac{2}{T}\left(\frac{2}{3} t_{A}+t_{C}\right)}
$$

- in the case where $k_{u}>1$

$I_{1}=\sqrt{\frac{2}{T}\left[\frac{1}{3} I_{L 3}^{2} t_{A}+\frac{1}{3} I_{L 2}^{2} t_{B}+\left(I_{L 2}^{2}+\frac{1}{3} \Delta I_{L}^{2}-I_{L 2} \Delta I_{L}\right) t_{C}\right]}$

where $\Delta I_{L}=I_{L 3}-I_{L 2}$.

All the time intervals $t_{A}, t_{B}$ and $t_{C}$, and the characteristic values of the instantaneous currents $I_{L 2}$ and $I_{L 3}$ can be determined based on the relationships below:

$$
\begin{gathered}
t_{A}=\frac{T}{4} \frac{n E_{1}+E_{2}(2 D-1)}{n E_{1}-E_{2}} \\
t_{B}=D \frac{T}{2}-t_{A} \\
t_{C}=\frac{T}{2}(1-D) \\
I_{L 2}=\frac{n E_{1}+E_{2}}{n L} t_{B} \\
I_{L 3}=\frac{n E_{1}+E_{2}}{n L} t_{A}
\end{gathered}
$$

b)

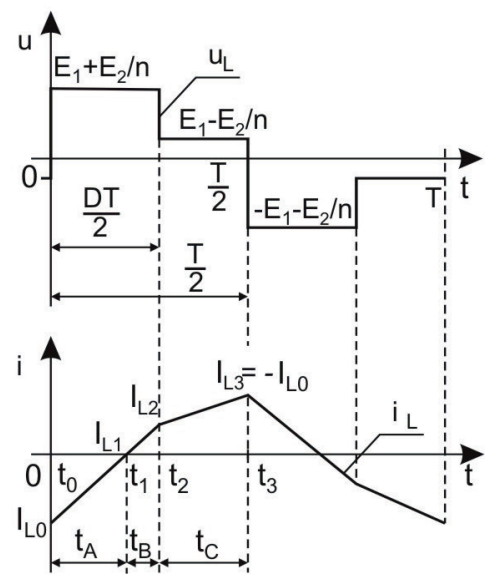

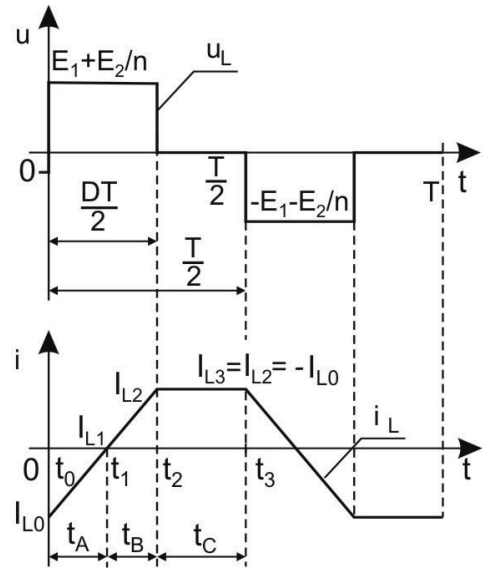

c)

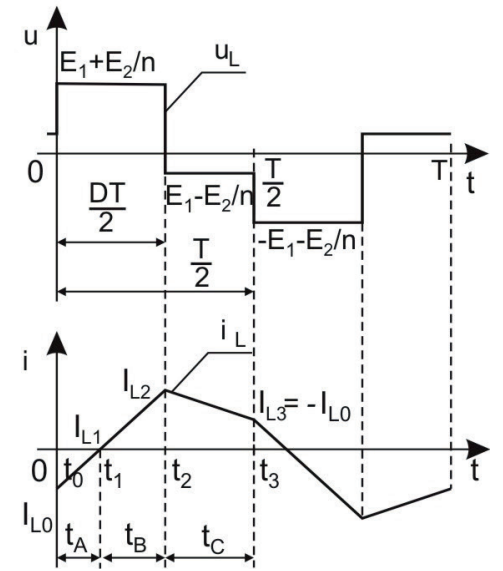

Fig. 15. The instantaneous values of voltage $u_{L}$ and current $i_{L}$ for: a) $E_{1}>E_{2} / n,\left(k_{u}<1\right)$; b) $E_{1}=E_{2} / n,\left(k_{u}=1\right)$; and c) $E_{1}<E_{2} / \mathrm{n},\left(k_{u}>1\right)$ 


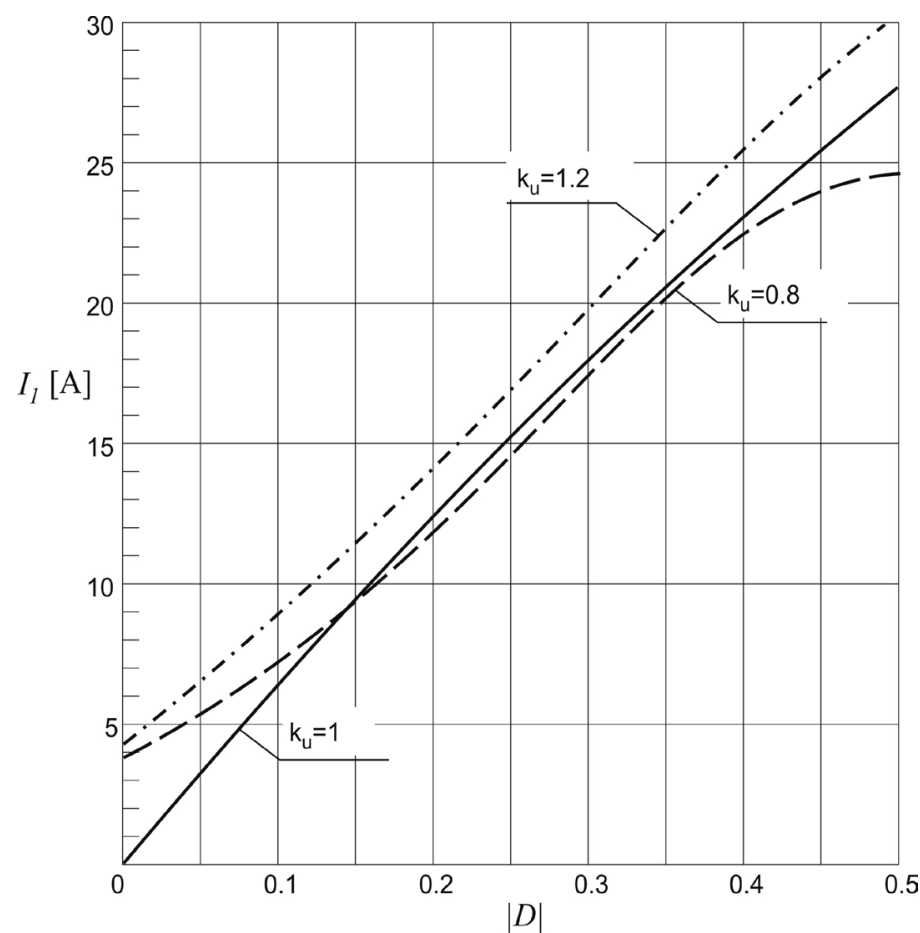

Fig. 16. The RMS value of current in the high-voltage (primary) winding of a transformer operating in the DAB converter as dependent on the shift ratio $D$ for different conversion ratios $k_{u}$

Taking into account the parameters of the system under consideration, the effective current in the high-voltage winding can be calculated for a different shift ratio $D$ and a varying conversion ratio $k_{u}$ (Fig. 16).

The waveform shapes of currents in transformer operating in the $\mathrm{DAB}$ converter are similar to triangular, exponential or trapezoidal ones. A simple method to achieve these currents is to pow- er supply the transformer from H-bridge converter in the cases: short - circuit operation (triangular shape), resistive load operation (exponential shape) and an inductive - load rectifier connected to the secondary winding (trapezoidal shape). For these waveforms, the RMS values of the individual winding current harmonics relative to the RMS value of the base harmonic are: $I_{(3)} / I_{(1)}=0.1 \div 0.25 ; I_{(5)} / I_{(1)}=0.05 \div 0.1 ; I_{(7)} / I_{(1)}=0.02 \div 0.05$; $I_{(9)} / I_{(1)}=0.015 \div 0.02 ; I_{(11)} / I_{(1)}=0.01 \div 0.015$. Although the AC winding resistances for each of the current harmonics are higher than for the base current components (Table 2), the power losses in the copper caused by the harmonics of the order $k>3$ are negligible.

5.3. Copper losses. Calculating the winding power losses by summing the losses caused by individual current harmonics (formula (11)) is very time-consuming. Therefore, an attempt was made to calculate the power dissipation in the windings based on the RMS of the winding currents $I_{1}$ and $I_{2}=I_{1} / n$. The calculations were performed for the windings resistance at 100 $\mathrm{kHz}$ according to the following formula:

$$
P_{C u}^{\prime}=I_{1}^{2} R_{a c 1(1)}+I_{2}^{2} R_{a c 2(1)}
$$

The relative percentage differences between the results of calculations based on the advanced formula (13) and the simplified relation (23), defined as

$$
\varepsilon_{R(1)}=\frac{P_{C u}-P_{C u}^{\prime}}{P_{C u}} 100 \%
$$

are presented in Fig. 17.

Due to the small difference between the calculations results (not exceeding 6\%) relative to the original inverter cooling system design, the power losses in the transformer windings can

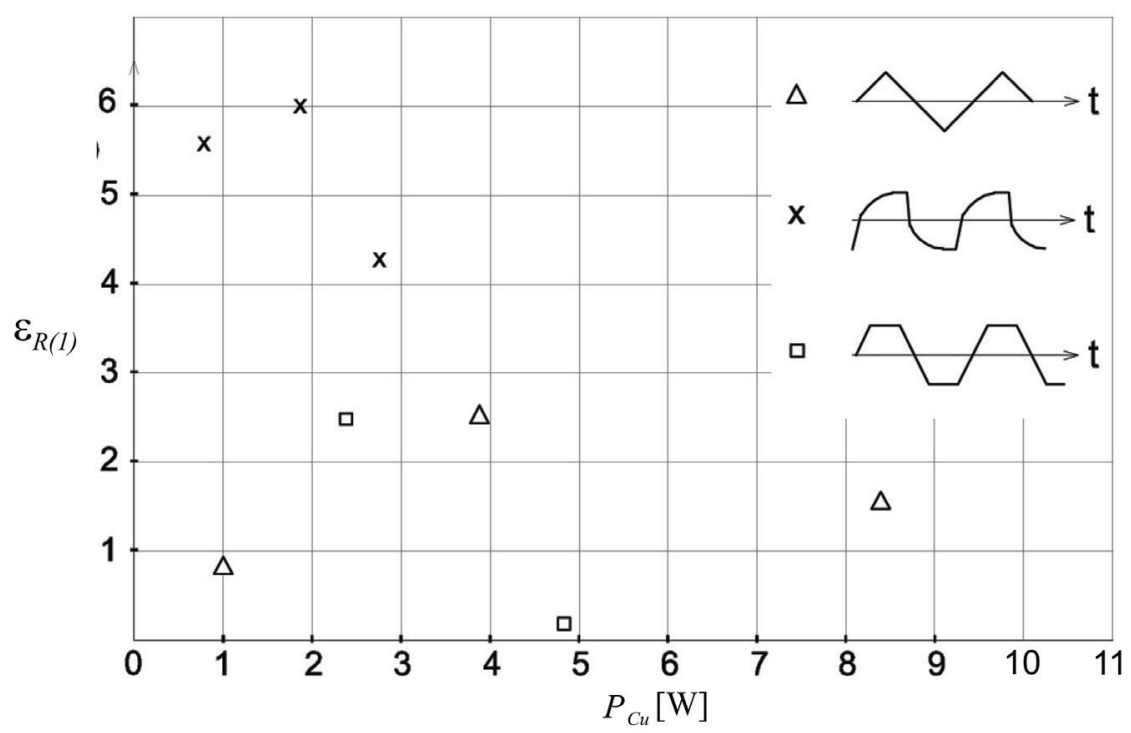

Fig. 17. Relative differences $\varepsilon_{R(1)}$ between the winding power loss calculation results obtained from formula (13) and (23) for currents of various waveforms $(\Delta-$ triangular, $\times$ - exponential and $\square-$ trapezoidal), as a function of the power loss as calculated from formula (13) 


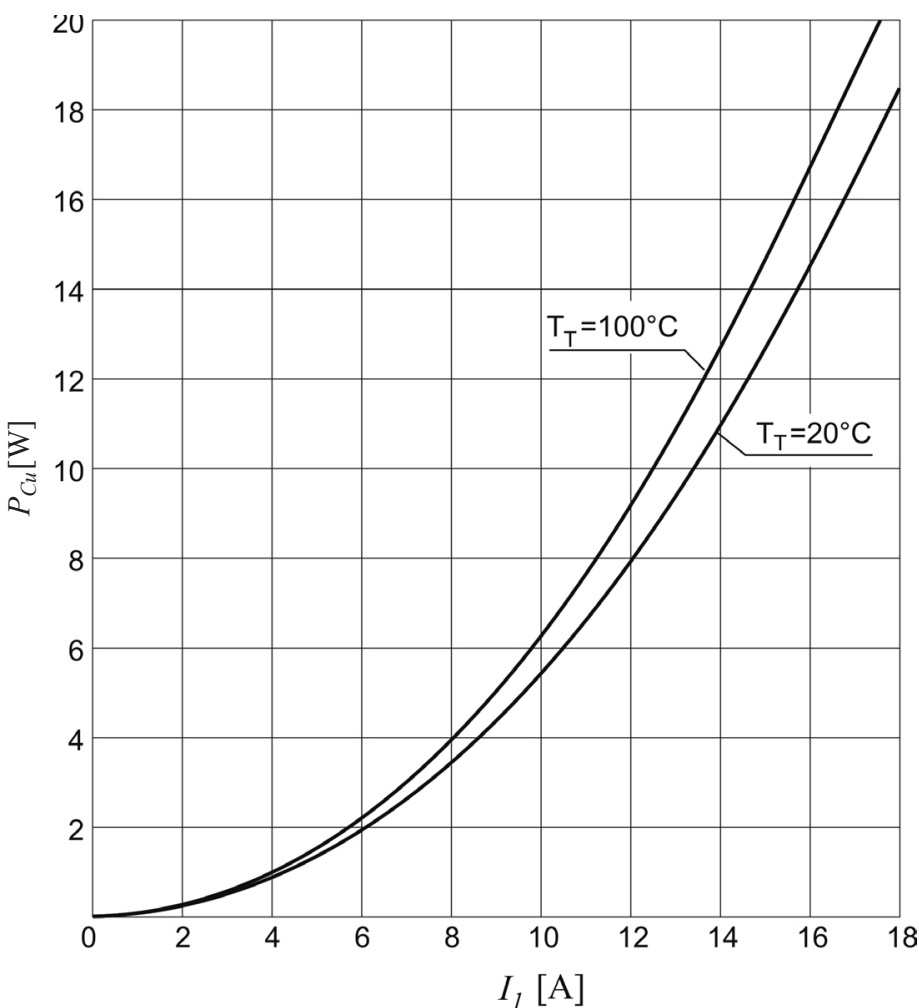

Fig. 18. Transformer winding power losses versus the RMS current in the primary winding for $20^{\circ} \mathrm{C}$ and $100^{\circ} \mathrm{C}$

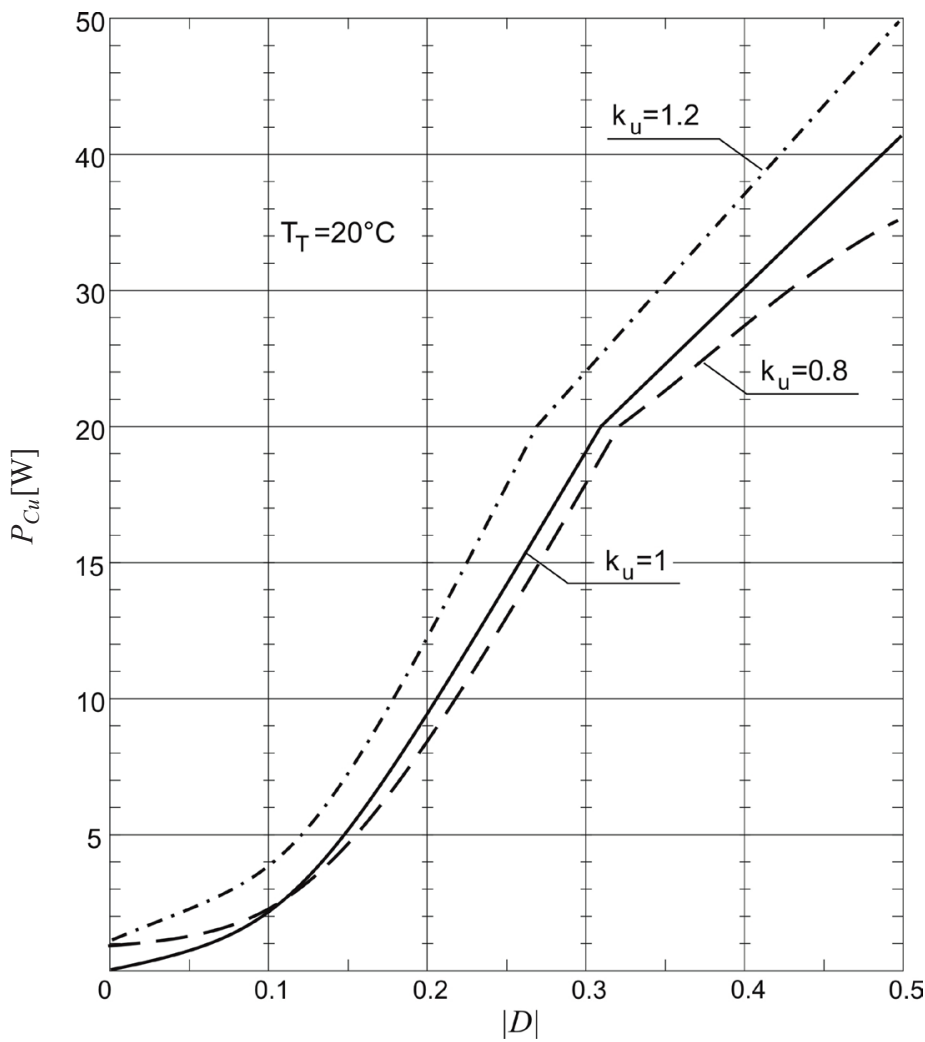

Fig. 19. Transformer copper losses in the DAB system as dependent on the shift ratio $D$ for different conversion ratios $k_{u}$ at $20^{\circ} \mathrm{C}$ be calculated based on the resistance $R_{a c 1(1)}$ and $R_{a c 2 \text { (1) }}$ and the RMS value of the currents $I_{1}$ and $I_{2}=I_{1} / n$.

The power losses in the windings of the transformer under consideration as a function of the RMS value of the primary current and as a function of the shift ratio $D$ for several conversion ratios $k_{u}$ are shown in Fig. 18 and Fig. 19.

The graphs in Figure 18 are universal and can be used regardless of the system in which the transformer under consideration operates.

The power losses generated in the windings at the temperature $100^{\circ} \mathrm{C}$ are only by approx. $15 \%$ higher than at $20^{\circ} \mathrm{C}$. This is due to the winding resistance increase for $\mathrm{AC}$ current $(100 \mathrm{kHz}$ ) being smaller than for DC current (for the temperature increase by $80^{\circ} \mathrm{C}$ the copper resistivity $\rho$ increases by approx. $32 \%$ ).

\section{Total power losses in the transformer operating in the DAB converter}

The total power loss $P_{T r}=P_{F e}+P_{C u}$ as dependent on the shift ratio $D$ for $k_{u}=0.8,1.0$ and 1.2 and for the temperature $100^{\circ} \mathrm{C}$ are given in the diagrams in Fig. 20.

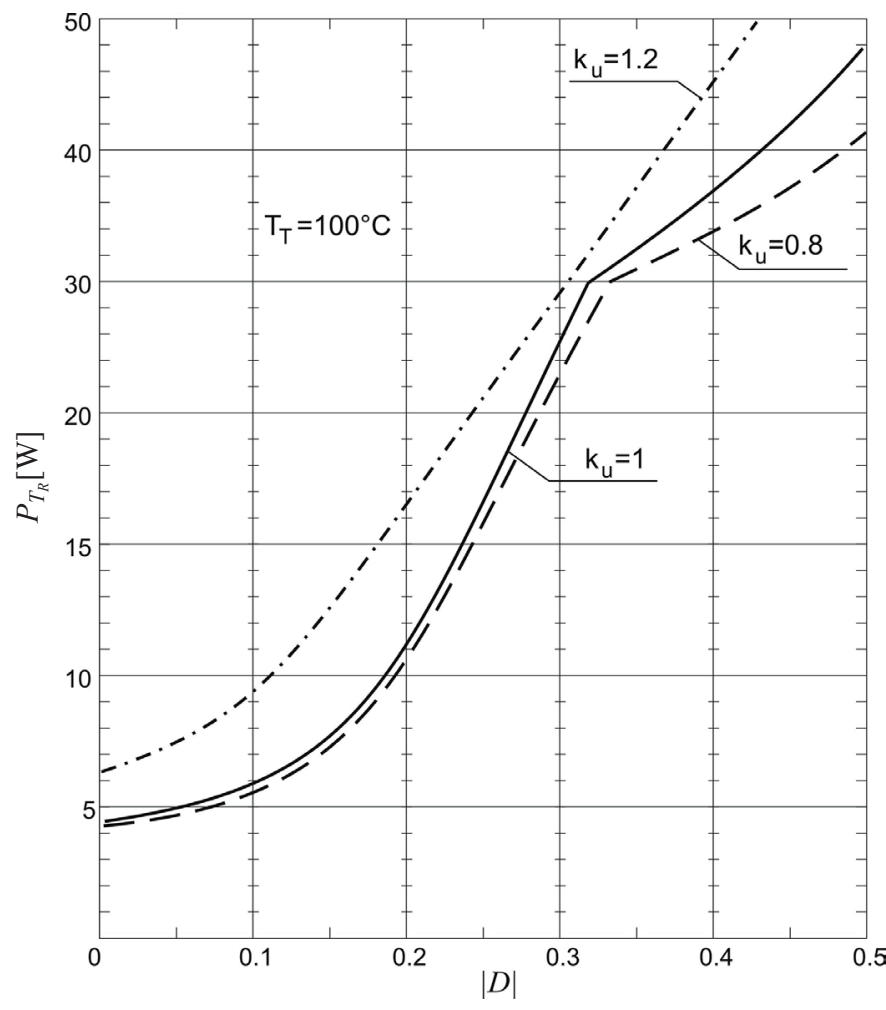

Fig. 20. The total power loss in the transformer operating in the DAB converter for the temperature $T_{T}=100^{\circ} \mathrm{C}$

For a small shift ratio of $(|D|<0.1)$, a dominant role is played by power losses in the transformer core. For a shift ratio of $|D| \geq 0.3$, the winding power losses are critical. By reducing 


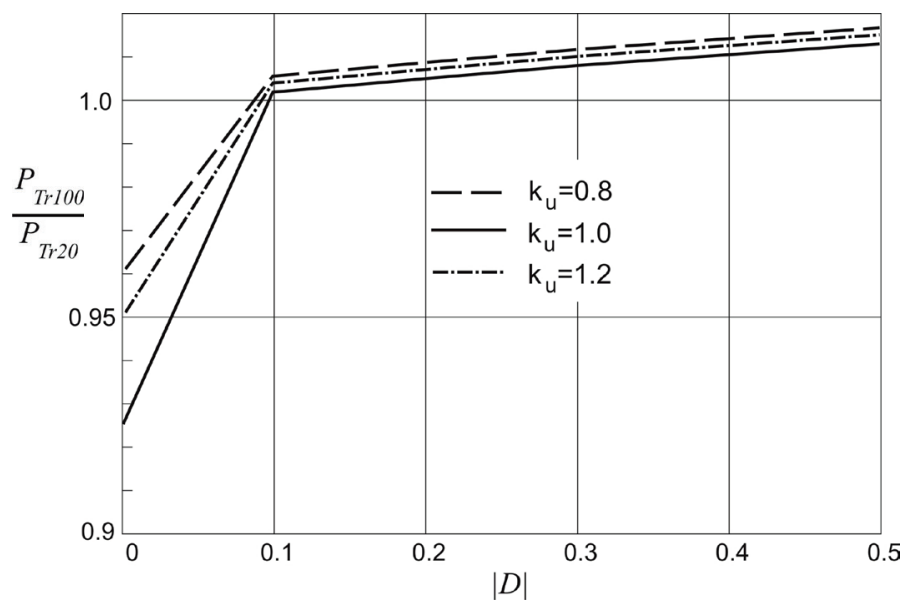

Fig. 21. Relationship between the total transformer power losses for a temperature of $100^{\circ} \mathrm{C}\left(P_{\operatorname{Tr} 100}\right)$ and $20^{\circ} \mathrm{C}\left(P_{T r 20}\right)$ vs. the shift ratio $D$ for several conversion ratios $k_{u}$

the transformer temperature, also the total power dissipation decreases (Fig. 21).

Taking into account the value of the power $P_{E}$ transmitted by the DAB converter between the DC circuits (eq. (1), Fig. 2) as well as the $P_{T r}$ power losses, the transformer energy efficiency $\eta$ is calculated as follows:

$$
\eta=\frac{P_{E}-P_{T r}}{P_{E}} 100 \%
$$

The calculated efficiency $\eta$ as a function of the shift ratio $D$ for several $k_{u}$ values and for the temperatures $20^{\circ} \mathrm{C}$ and $100^{\circ} \mathrm{C}$ is shown in Fig. 22.

The obtained results confirm the existence of an important advantage of the planar transformer under discussion, that is the high energy efficiency, which is achieved owing to the proper design of the windings and the carefully selected core.

The calculated efficiency values are fully consistent with the specifications guaranteed by the manufacturer (99.7\%). It should be noted that the transformer has high energy efficiency only for a specific, narrow range of shift ratios $D$.

\section{Comparison of the analytical and experimental results}

The analytically determined transformer power losses were verified experimentally in an indirect way by measuring the $P_{E 1}$ and $P_{E 2}$ power values in both coupled DC circuits. The measurements were made using DC voltmeters and ammeters $\left(P_{E 1}=E_{1} I_{1} ; P_{E 2}=E_{2} I_{2}\right)$ and wattmeters (VOLTECH), each time determining the average of the obtained measurements. The power losses in the semiconductor devices of the DAB converter were measured using an infrared camera [26].

The values of transformer power losses $P_{T r(\text { mea })}$ were determined indirectly from the relationship: a)

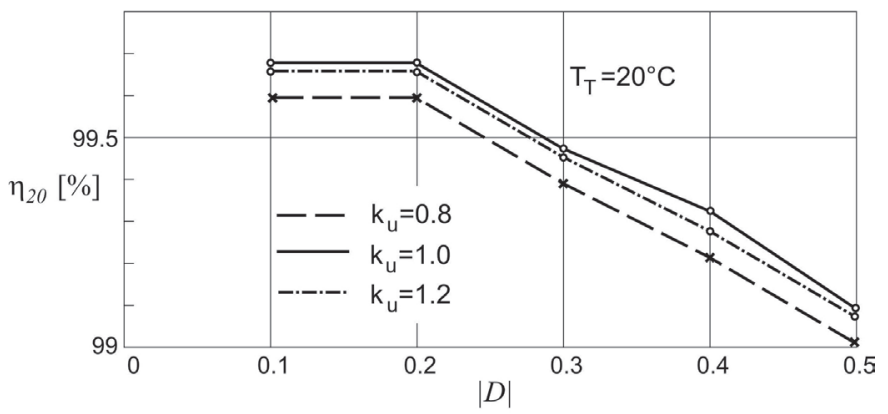

b)

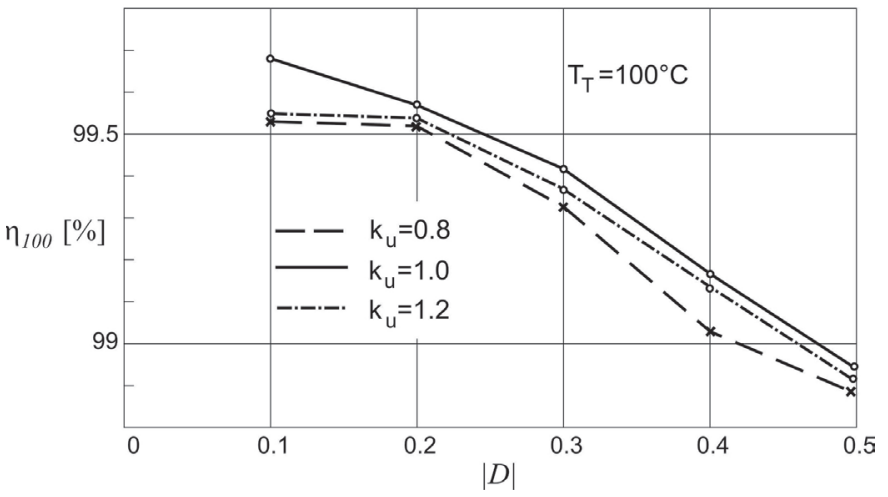

Fig. 22. Transformer efficiency variation with $D$ shift ratio for several $k_{u}$ values, namely: $k_{u}=0.8,1.0$ and $1.2:$ a) $T_{T}=20^{\circ} \mathrm{C}$; b) $T_{T}=100^{\circ} \mathrm{C}$

$$
P_{T r(\text { mea })}=\left|P_{E 1}-P_{E 2}\right|-2 P_{L}-P_{\text {semi }}-P_{\text {bus }}
$$

where $P_{\text {semi }}$ - power losses generated in the semiconductor devices; $P_{L}$ - power losses in the two additional inductors connected to the transformer primary circuit, $P_{b u s}-$ power losses in the DC bus of the DAB.

The power losses generated in the additional two inductors were determined analytically by calculating the power losses in the cores $\left(P_{F e L}\right)$ and in the windings $\left(P_{C u L}\right)$. The inductors were made using a shell-like ferrite core with parameters corresponding to those of $3 \mathrm{~F} 3$ material.

Similarly as in the case of the transformers, the power losses in the reactor core depend on the peak value and frequency of induction and the type and volume of material used to build the core. The peak value of the induction $B_{m L}$ can be calculated based on the voltage across the winding of the inductor with a known inductance.

The voltage on one of the inductors with an inductance $L_{d 1}$ can be determined using the following formulas (Fig. 1):

$$
\begin{gathered}
u_{L d 1}=k_{L 1}\left(u_{1}-u_{2}^{\prime}\right) \\
k_{L 1}=\frac{L_{d 1}}{2 L_{\sigma}+L_{d 1}+L_{d 2}}=\frac{L_{d 1}}{L}
\end{gathered}
$$

where $L_{d 1}, L_{d 2}$ - inductances of the additional inductors; $u_{2}^{\prime}=u_{2} / n$. 
a)

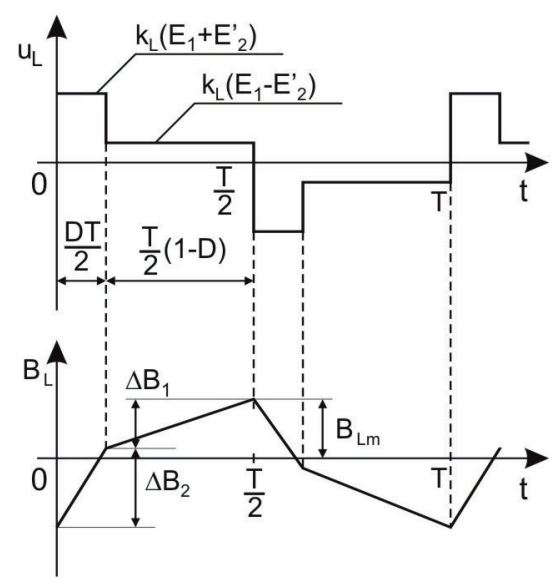

b)

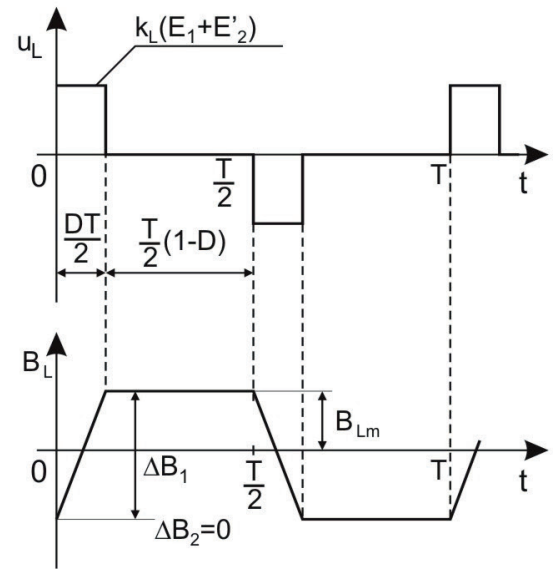

c)

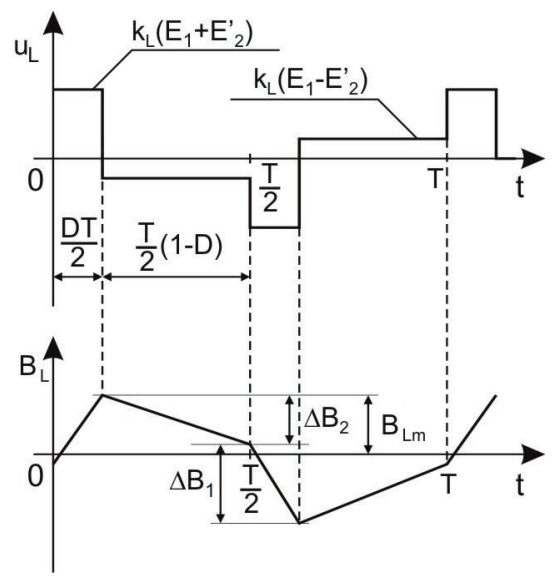

Fig. 23. The simplified waveforms of winding voltage and induction in the core of one of the inductors on the primary transformer side: a) $k_{u}<1$; b) $k_{u}=1$; c) $k_{u}>1$

In the system under discussion, the following relationships are satisfied: $L_{d 1}=L_{d 2}=L_{d} / 2 ; L_{d}=L_{d 1}+L_{d 2}=20.1 \mu \mathrm{H}$; $k_{L 1}=k_{L 2}=k_{L}=L_{d} / 2 L ; L=2 L_{\sigma}+L_{d}=21 \mu \mathrm{H}$.

The Figure 23 shows voltage waveforms on one of the inductors and the corresponding instantaneous induction values, of which maximum value is defined by the formula

$$
\begin{aligned}
B_{m L}= & \frac{\Delta B_{1}+\Delta B_{2}}{2}= \\
= & \left\{\begin{array}{c}
A\left[1+k_{u}(2 D-1)\right] \ldots . . \text { for } \ldots \ldots k_{u}<1 \\
A\left(1+k_{u}\right) D \ldots \ldots \ldots \ldots \text { for } \ldots \ldots . . . k_{u}=1 \\
A\left(2 D+k_{u}-1\right) \ldots \ldots \text { for } \ldots \ldots . k_{u}>1
\end{array}\right.
\end{aligned}
$$

where

$$
A=\frac{T E_{1}}{4 S_{F e L} N} k_{L}
$$

where $S_{F e L}$-inductor core cross-section; $N$ - the number of turns.

The power losses generated in the core of each of the inductors were calculated from formula (4) using the following data: $S_{F e}=265 \times 10^{-6} \mathrm{~m}^{2} ; V_{F e L}=18.2 \mathrm{~cm}^{3} ; N=8 ; k_{L}=0.4785$; $T=10 \times 10^{-6} \mathrm{~s} ; T_{T}=100^{\circ} \mathrm{C}$.

The windings of these inductors were made from three litz wire conductors connected in parallel, each consisting of 120 thin wires with a diameter of $d=0.07 \mathrm{~mm}$.

Due to the fact that the $d$ diameter is much smaller than the copper skin depth ( $\delta \approx 0.22 \mathrm{~mm}$ for $100 \mathrm{kHz})$, for the calculation of the power losses dissipated in the inductor windings it can be assumed that $\mathrm{AC}$ current resistance $\left(R_{a c L}\right)$ is equal to the $\mathrm{DC}$ current resistance $R_{d c L}=5.21 \mathrm{~m} \Omega$ (at $100^{\circ} \mathrm{C}$ ).

The power losses in the winding of a single inductor, $P_{C u L}$, were calculated taking into account the RMS values of the current $I_{l}$ flowing in the primary winding (Fig. 16).
The total power dissipated in a single inductor, $\left(P_{L}=P_{F e L}{ }^{+}\right.$ $\left.P_{C u L}\right)$, as a function of the shift ratio $D$ for three characteristic coefficients $k_{u}$ is shown in Fig. 24.

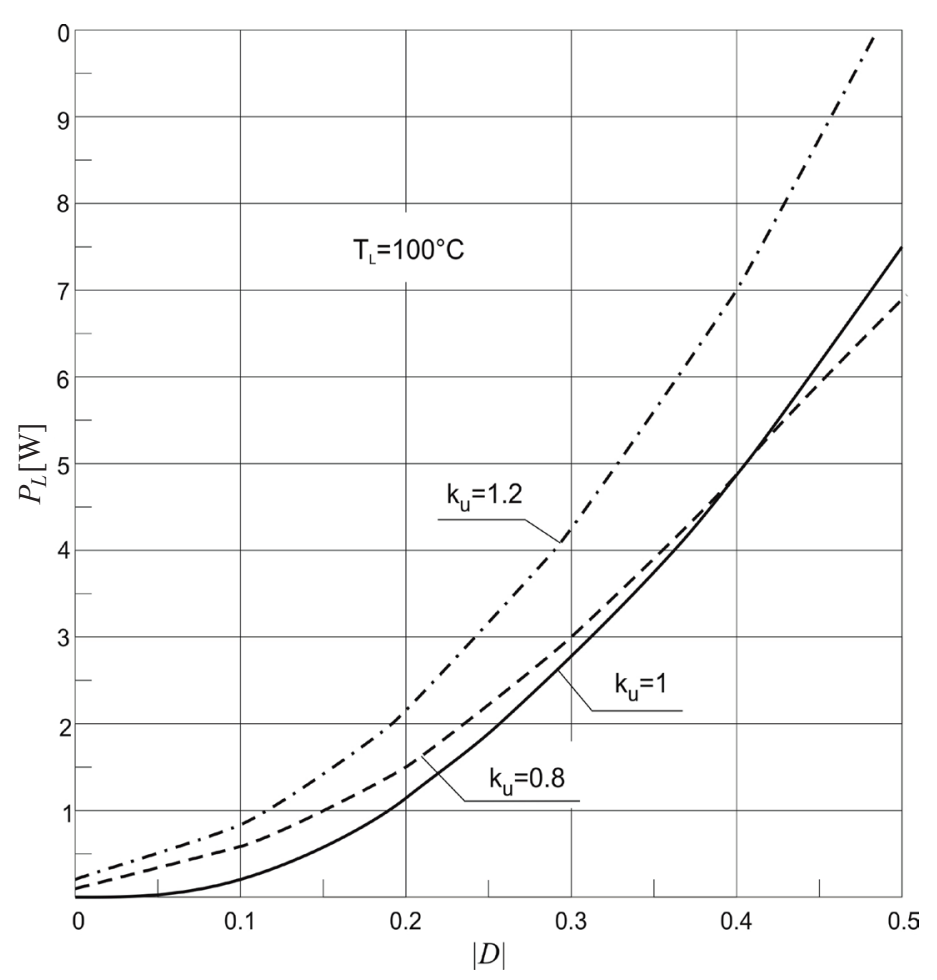

Fig. 24. Power losses in one of the two inductors arranged in the AC circuit of the DAB converter

Table 3 presents the power loss calculation and measurement results and the absolute $\left(\Delta P_{T r}=P_{T r}-P_{T r(m e a)}\right)$ and the relative $\left(\delta_{P T \mathrm{r}}\right)$ differences between the analytical and experimental results obtained for the identical $D$ ratio and $k_{u}$ values. 
Table 3

Results of the measurements and calculations of power losses in the DAB system

\begin{tabular}{|c|c|c|c|c|c|c|c|c|c|c|}
\hline$k_{u}$ & $D$ & $P_{E 1}-P_{E 2}$ & $2 P_{L}$ & $P_{\text {semi }}$ & $P_{\text {bus }}$ & $P_{T r(\text { mea })}$ & $P_{T r(m e a)}$ & $P_{T r}$ & $\Delta P_{T r}$ & $\delta_{P T r}$ \\
\hline- & - & W & W & W & $\mathrm{W}$ & W & W & W & W & $\%$ \\
\hline \multirow{2}{*}{1.0} & \multirow{2}{*}{0.11} & 57.4 & 0.5 & 47.6 & 1.22 & 8.08 & \multirow{2}{*}{5.6} & \multirow{2}{*}{6} & \multirow{2}{*}{0.4} & \multirow{2}{*}{6.66} \\
\hline & & 70.7 & 0.5 & 65.9 & 1.17 & 3.13 & & & & \\
\hline \multirow{2}{*}{1.2} & 0 & 106.5 & 0.6 & 98 & 0.35 & 7.55 & 7.55 & 6.5 & -1.05 & -16.15 \\
\hline & 0.03 & 120.3 & 0.9 & 112.7 & 0.58 & 6.12 & 6.12 & 6.7 & 0.58 & 8.65 \\
\hline
\end{tabular}

The relative differences between the theoretical and experimental results were calculated using the formula

$$
\delta_{P T r}=\frac{P_{T r}-P_{T r(\text { mea })}}{P_{T r}} 100 \%=\frac{\Delta P_{T r}}{P_{T r}} 100 \%
$$

Being aware of the imperfection of the adopted power loss measurement method, which is due to the class of accuracy of the measuring instruments used (an absolute error of measuring power at a level of $2 \mathrm{~kW}$ using a wattmeter in DC circuits may reach values of several watts), a difference between analytical calculation and experimental measurement results of $\left(\left|\delta_{P T \mathrm{r}}\right|<20 \%\right)$ can be considered acceptable. The analytical relationships presented in this paper can therefore be used to estimate the power losses in the magnetic elements of the DAB system.

\section{Conclusions}

The presented analytical description using Steinmetz's and Dowell's formulas has enabled the calculation of the power losses generated in a $5600 \mathrm{VA} / 100 \mathrm{kHz}$ planar transformer operating in the DAB system. It has been shown that the power losses in the windings can be calculated based on the effective currents without having to determine the winding resistances for primary and secondary current harmonics. The power losses calculated by summing the losses for each harmonic component and based on the RMS currents differ by less than $6 \%$.

The analytical calculation results for transformer power loss and energy efficiency are fully consistent with the specifications provided in the data sheets of the transformer under consideration. They show good agreement with the experimental investigation results (the maximum relative difference does not exceed $20 \%$ ). This provides grounds for using relatively simple analytical formulas for the evaluation of the power loss in various components of the $\mathrm{DAB}$ converter with varying shift ratios and different relationships between the direct current circuit voltages. This may facilitate the process of designing the system, and especially its cooling system.

Acknowledgements. This research was supported by the Polish Ministry of Science and Higher Education within the frame-

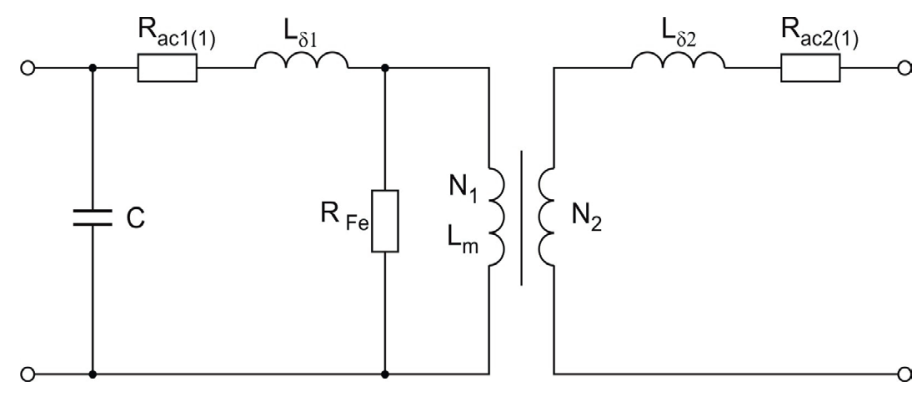

Fig. 25. Equivalent transformer circuit for $f=100 \mathrm{kHz}$ and $u_{1}= \pm 280 \mathrm{~V}$

work of the statutory activity (Institute of Control and Industrial Electronics, Warsaw University of Technology, 2014) and partially by the Polish National Science Centre (2010-2013).

Appendix. The equivalent transformer circuit for $f=100 \mathbf{k H z}$ and $\mathbf{u} \mathbf{1}= \pm \mathbf{2 8 0} \mathrm{V}$. To determine the basic parameters (Table 4), the transformer was tested under no-load and short-circuit conditions with $100 \mathrm{kHz}$ rectangular voltage (Fig. 25).

Table 4

Basic parameter of the tested transformer

\begin{tabular}{|l|l|}
\hline Parameter & Value \\
\hline$R_{a c 1(1)}$ & $15 \mathrm{~m} \Omega$ \\
\hline$R_{a c 2(1)}$ & $1.4 \mathrm{~m} \Omega$ \\
\hline$R_{F e}$ & $12.6 \mathrm{k} \Omega$ \\
\hline$L_{\delta 1}$ & $0.76 \mu \mathrm{H}$ \\
\hline$L_{\delta 2}$ & $0.025 \mu \mathrm{H}$ \\
\hline$L_{m}$ & $770 \mu \mathrm{H}$ \\
\hline$C$ & $0.13 \mathrm{nF}$ \\
\hline
\end{tabular}

\section{REFERENCES}

[1] F. Blaabjerg, R. Teodorescu, M. Liserre, and A. Timbus, “Overview of control and grid synchronization for distributed power generation systems", IEEE Trans. Ind. Electron. 53 (5), 1398-1409 (2006). 
[2] S. P. Engel, N. Soltau, H. Stagge and R. W. De Doncer, "Dynamic and balanced control of three-phase high-power dual-active bridge dc-dc converters in dc-grid applications", IEEE Trans. Power Electron. 28(4), 1880-1889 (2013).

[3] B. Zhao, Q. Song and W. Liu, "Efficiency characterization and optimization of isolated bidirectional DC-DC converter based on dual-phase-shift control for DC distribution application”, IEEE Trans. Power Electron. 28(4), 1711-1727 (2013).

[4] B. Zhao, Q. Yu and W. Sun, "Extended-phase-shift control of isolated bidirectional dc-dc converter for power distribution in microgrid", IEEE Transactions on Power Electronics 27(11), 4667-4680 (2012).

[5] M. Nowak, J. Hildebrandt and P. Łuniewski, "Converters with $\mathrm{AC}$ transformer intermediate link suitable as interfaces for supercapacitor energy storage", Proc. IEEE Power Electron. Spec. Conf. 5, 4067-4073 (2001).

[6] F. Krismer and J. W. Kolar, "Accurate power loss model derivation of a high-current dual active bridge converter for an automotive application", IEEE Trans. Ind. Electron. 57 (3), 881-891 (2010).

[7] R. T. Naayagi, A. J. Forsyth and R. Shuttleworth, "High-power bidirectional DC-DC converter for aerospace applications", IEEE Transactions on Power Electronics, 27(11), 2276-2287 (2012).

[8] R. De Doncer, D. Divan and M. Kheraluwala, "A three-phase soft switched high-power-density DC/DC converter for high-power applications", IEEE Trans. Ind. Appl. 27(1), 63-73 (1991).

[9] R. Barlik, M. Nowak, P. Grzejszczak, "Power transfer analysis in a single phase dual active bridge", Bull. Pol. Ac.: Tech., 61(4), 809-828 (2013).

[10] F. Krismer and J. W. Kolar, "Closed form solution for minimum conduction loss modulation of DAB converters", IEEE Trans. Power Electron. 27(1), 174-188 (2012).

[11] M. Sippola and R. S. Sepponen, "Accurate prediction of high-frequency power transformer losses and temperature rise", IEEE Trans. Power Electron. 17(5), 835-847 (2002).

[12] M. A. Bahmani, T. Thiringer, H. Ortega, "An accurate Pseudoempirical Model of Winding Loss Calculation in HF Foil and Round Conductors in Switch mode Magnetics", IEEE Transactions on Power Electronics, 29(8), 4231-4236 (2014).

[13] Y. Han, W. Eberle and A. Liu, "A practical copper loss measurement method for the planar transformer in high-frequency switching converters", IEEE Transactions on Industrial Electronics 54(4), 2276-2287 (2007).
[14] A. Stadler and Ch. Gulden, "Improved thermal design of a high frequency power transformer", Proc. of the 14thEuropean Conference on Power Electronics and Applications (2011).

[15] I. Villar, U. Viscarret, I. Etxeberria-Otadui and A. Rufer, "Global loss evaluation methods for nonsinusoidally fed medium-frequency power transformers", IEEE Trans. Ind. Electron. 56(10), 4132-4140 (2009).

[16] D. K. Conroy, G. F. Pierce and P. R. Troyk, "Measurement techniques for the design of high-frequency SMPS transformers", Proc. IEEE 3rd Annu. Power Electron. Conf., 341-351 (1988).

[17] M. Nowak, P. Grzejszczak, M. Zdanowski and R. Barlik, "The thermovision metod for windings power losses assessment of high frequency planar transformer", Przeglad Elektrotechniczny 88(11), 60-63 (2012).

[18] J. Reinert, A. Brockmeyer and R. W. A. A. De Doncer, "Accurate calculation of power losses in ferro- and ferromagnetic materials based on the modified Steinmetz equation", IEEE Trans. Ind. Appl. 37(4), 1055-1060 (2001).

[19] P. Dowell, "Effects of eddy currents in transformer windings", Proc. IEEE 113(8), 1387-1394 (1966).

[20] G. G. Oggier, G. O. Garcia, and A. R. Oliva, „Switching control strategy to minimize dual active bridge converter losses", IEEE Trans. Power Electron. 24(7), 1826-1838 (2009).

[21] R. Petkov, "Optimum design of a high-power, high-frequency transformer", IEEE Trans. Power Electron. 11(1), 33-42, (1996).

[22] J.A. Ferreira, "Improved analytical modeling of conductive losses in magnetic components", IEEE Trans. on Power Electronics 9(1), 127-131 (1994).

[23] H. Rossmanith, M. Doebroenti, M. Albach and D. Exner, "Measurement and characterization of high frequency losses in nonideal litz wires", IEEE Trans. Ind. Electron. 26(11), 3386-3394 (2011).

[24] Z. Ouyang, O. C. Thomsen and M. A. E. Andersen, "Optimal design and tradeoff analysis of planar transformer in high - power dc-dc converters", IEEE Trans. Ind. Electron. 59(7), 2800-2810 (2012).

[25] W. G Hurley, W. H. Wölfe and J. O. Breslin, "Optimized transformer design: inclusive of high-frequency effects", IEEE Transactions on Power Electronics 13(4), 651-659 (1998).

[26] M. Nowak, Grzejszczak P., Zdanowski M., Barlik R., "Thermal measurement for verification of Power loss in semiconductor switching devices", Przegląd Elektrotechniczny 88(4b), 163-168 (2012).

[27] www.standexelectronics.com (2013). 